\title{
Isolation of high affinity human antibodies directly from large synthetic repertoires
}

\author{
Andrew D.Griffiths', Samuel C.Williams², \\ Oliver Hartley ${ }^{1}$, Ian M.Tomlinson ${ }^{1}$, Peter \\ Waterhouse ${ }^{1,6}$, William L.Crosby 1,5, Roland \\ E.Kontermann', Peter T.Jones', Nigel \\ M.Low², T.John Allison'2, Terence \\ D.Prospero', Hennie R.Hoogenboom ${ }^{1,4}$, \\ Ahuva Nissim ${ }^{1}$, Jonathan P.L.Cox ${ }^{1,7}$, \\ Jacqueline L.Harrison', Manuela Zaccolo ${ }^{3}$, \\ Ermanno Gherardi ${ }^{3}$ and Greg Winter ${ }^{1,2}$
}

\begin{abstract}
${ }^{1} \mathrm{MRC}$ Centre for Protein Engineering, ${ }^{2} \mathrm{MRC}$ Laboratory of Molecular Biology and ${ }^{3}$ ICRF Cell Interactions Laboratory, MRC Centre, Hills Road, Cambridge CB2 2QH and ${ }^{4}$ Cambridge Antibody Technology Ltd, The Science Park, Melbourn, Cambridgeshire SG8 6EJ, UK

Present address: ${ }^{5}$ National Research Council of Canada, Plant Molecular Genetics, 110 Gymnasium Road, Saskatoon, Saskatchewan, Canada S7N-0W9, 6 CSIRO Division of Plant Industry, GPO Box 1600, Canberra ACT 2601, Australia and ${ }^{7}$ University of Bath, School of Chemistry, Claverton Down, Bath BA2 7AY, UK

Communicated by G.Winter
\end{abstract}

Antibody fragments of moderate affinity $(\sim \mu \mathrm{M})$ can be isolated from repertoires of $\sim 1^{8}$ immunoglobulin genes by phage display and rounds of selection with antigen, and the affinities improved by further rounds of mutation and selection. Here, as an alternative strategy, we attempted to isolate high affinity human antibodies directly from large repertoires. We first created highly diverse repertoires of heavy and light chains entirely in vitro from a bank of human $\mathrm{V}$ gene segments and then, by recombination of the repertoires in bacteria, generated a large $\left(\right.$ close to $\left.6.5 \times 10^{10}\right)$ synthetic repertoire of Fab fragments displayed on filamentous phage. From this repertoire we isolated Fab fragments which bound to a range of different antigens and haptens, and with affinities comparable with those of antibodies from a secondary immune response in mice (up to $4 \mathrm{nM}$ ). Although the VH-26 (DP-47) segment was the most commonly used segment in both artificial and natural repertoires, there were also major differences in the pattern of segment usage. Such comparisons may help dissect the contributions of biological mechanisms and structural features governing $\mathrm{V}$ gene usage in vivo. Key words: high affinity/human antibodies/phage

\section{Introduction}

The display on the surface of filamentous bacteriophage (Smith, 1985) of antibody fragments (McCafferty et al., 1990; Barbas et al., 1991; Breitling et al., 1991; Garrard et al., 1991; Hoogenboom et al., 1991) by fusion to a minor coat protein of phage (pIII), and selection of the phage with antigen, has provided a powerful means of making antibodies of predefined binding specificity from $\mathrm{V}$ gene repertoires (for review see Winter et al., 1994). Starting from repertoires derived from the $\mathrm{V}$ genes of an immune response, antibody fragments have been readily isolated with high affinity (Clackson et al., 1991), and even with neutralizing activities against virus (Barbas et al., 1992a,b).

The display and selection of antibody fragments on the surface of phage mimics immune selection (for review see Marks et al., 1992a), and antibodies have also been isolated without immunization, from repertoires of $\mathrm{V}$ genes rearranged in vivo (Marks et al., 1991) or in vitro (Hoogenboom and Winter, 1992). The same phage repertoire may be used to generate many different binding specificities, including those that are difficult to raise by immunization, for example against self-antigens (Griffiths et al., 1993; Marks et al., 1993) or proteins of the lumen of the endoplasmic reticulum (Nissim et al., 1994). Antibodies from such 'single pot' libraries appear to be highly specific and have been used for 'on-line detection' of antigen in biosensors (M.Malmqvist, unpublished), and for Western blotting and epitope mapping (Nissim et al., 1994). But the affinities were not high $(\sim \mu \mathrm{M})$, as expected for primary repertoires of $10^{7}-10^{8}$ clones.

It should also be possible to isolate high affinity antibodies $(<10 \mathrm{nM})$ directly from primary repertoires of sufficiently large diversity and size (Perelson and Oster, 1979), but the size and diversity of repertoires required is not known. The size and 'shape' of natural repertoires is limited not only by the number of B-lymphocytes $\left(\sim 5 \times 10^{8}\right.$ in mouse and $\sim 10^{12}$ in human), and the number of lymphocytes in each clone, but also by the processes of clonal deletion and anergy that lead to self tolerance (for review see Nossal, 1993).

Here we constructed a highly diverse combinatorial repertoire entirely in vitro, using $\mathrm{V}$ gene segments as building blocks. We used the vast majority of heavy and light chain segments used in vivo and encoded part, or all, of each CDR3 loop by random sequence. To make the repertoire as large as possible we infected bacteria harbouring a 'donor' heavy chain repertoire (on a plasmid) with an 'acceptor' light chain repertoire (on phage). The two chains were combined on the same (phage) replicon within the bacterium by Cre catalysed recombination at loxP sites. This process, termed 'combinatorial infection' (Waterhouse et al., 1993), generates a large number of heavy and light chain combinations, potentially as large as the number of bacteria that have been infected. The repertoire was characterized by the properties of the selected Fab fragments. 


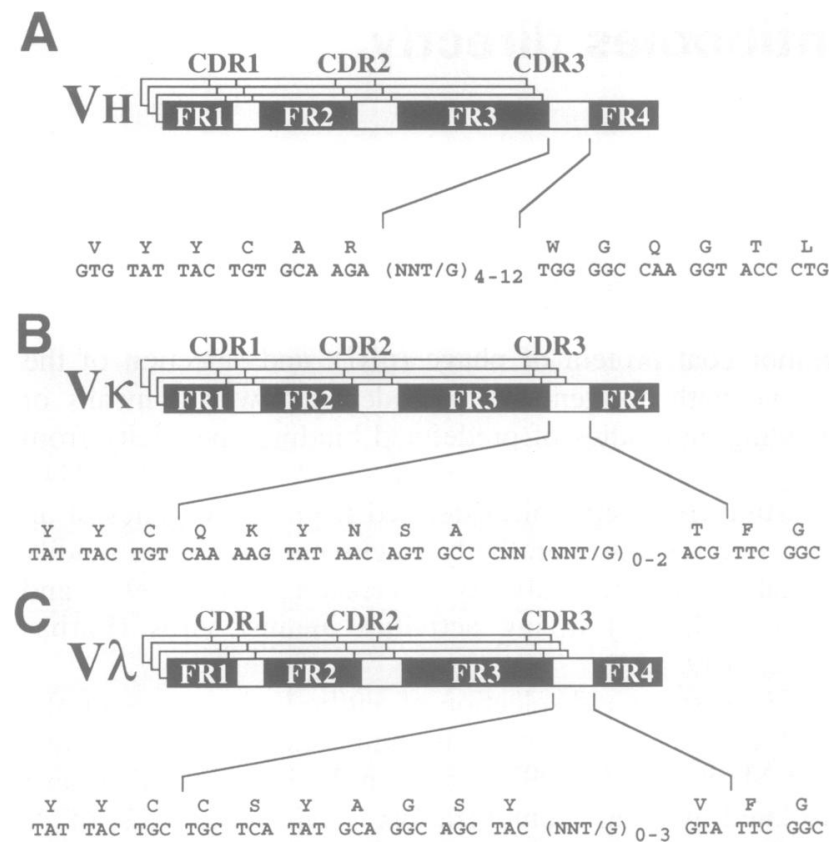

Fig. 1. Construction of synthetic heavy and light chain repertoires. (A) The repertoire of heavy chains ( $>10^{8}$ different clones) was built from 49 cloned $V_{H}$ segments (Tomlinson et al., 1992; Nissim et al., 1994), with CDR3 loops of four to 12 residues of random sequence. (B) The repertoire of $\kappa$ light chains $\left(9 \times 10^{4}\right.$ clones) was built from 26 cloned $\mathrm{V}_{\mathrm{K}}$ segments (Cox et al., 1994) with CDR3 loops of eight to 10 residues that included one, two or three residues of random sequence in all cases. DPK-4 is shown by way of an example. (C) The repertoire of $\lambda$ light chains $\left(7.4 \times 10^{5}\right.$ clones) was built from 21 cloned $V_{\lambda}$ segments (Williams and Winter, 1993), with CDR3 loops of eight to 13 residues that included zero, one, two, three, four or five residues of random sequence. DPL-12 is shown by way of example. CDR, complementarity determining region; FR, framework region. Neither the single segment of the $V_{k} 7$ subgroup, nor the few segments from the $V_{\lambda}$ families 4,5 or 6 , were included in the repertoire. Segments rarely used in vivo, for example light chain segments (DPK-2, -7, $-10,-12,-17,-19,-20,-23$ and -25$)$ from the distal $V_{K}$ locus (Cox et al., 1994), were represented equally in the synthetic repertoire. Some of the $V_{H}$ gene segments (DP-1, -12, $-30,-39,-40,-44,-45$ and -69) included in the repertoire are now known to be located on chromosomes 15 or 16 , and therefore outside the functional locus (Tomlinson et al., 1994).

\section{Results}

\section{Repertoire size and diversity}

Heavy and light chain repertoires were built from the majority of human $\mathrm{V}$ gene segments as described in Figure 1. The light chain repertoire was cloned into 'acceptor' fd phage (tetracycline resistant), with a 'dummy' heavy chain (Figure 2A), and the heavy chain repertoire into 'donor' plasmid (ampicillin resistant) (Figure 2B). The repertoires, $>10^{8}$ heavy chains and $>8 \times 10^{5}$ light chains, were combined by infection of Escherichia coli harbouring the donor heavy chains with fd phage carrying the light chains. If every heavy chain were paired with every light chain, this would generate a repertoire of $>8 \times 10^{13}$ antibodies. The culture was then co-infected with bacteriophage P1 (chloramphenicol resistant), which provides the Cre recombinase (Waterhouse et al., 1993), leading to $6.5 \times 10^{10}$ colonies resistant to ampicillin, tetracycline and chloramphenicol (for summary, see Table I). After growth of the cultures, the fd phage were used to infect E.coli. Twenty-eight per cent of the acceptor phage were shown to have acquired a heavy chain from the donor vector (see

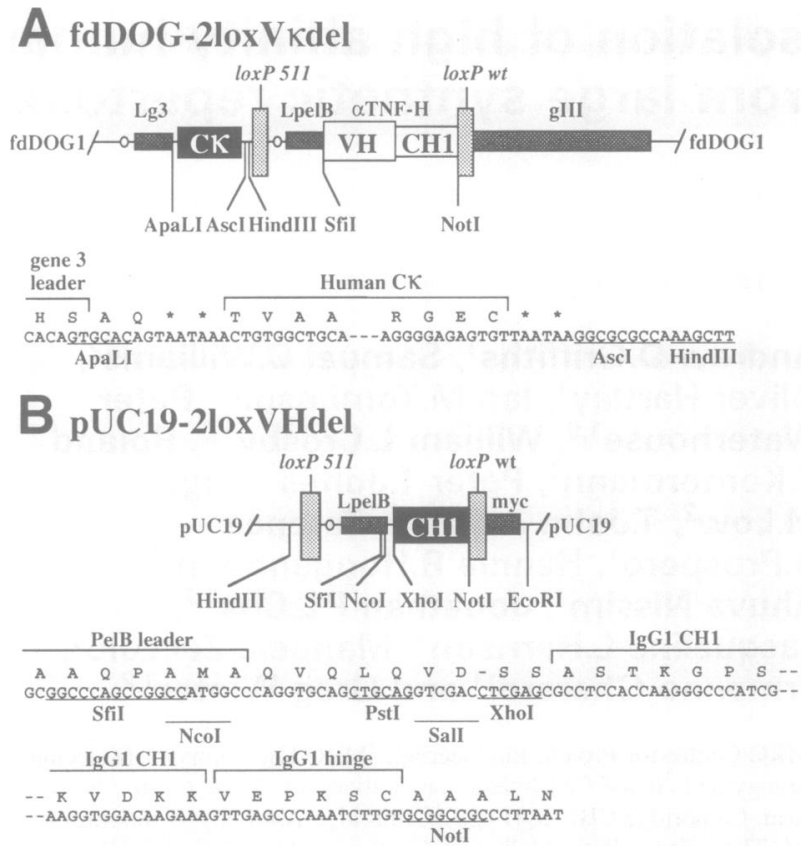

\section{C pUC119His6mycXba}

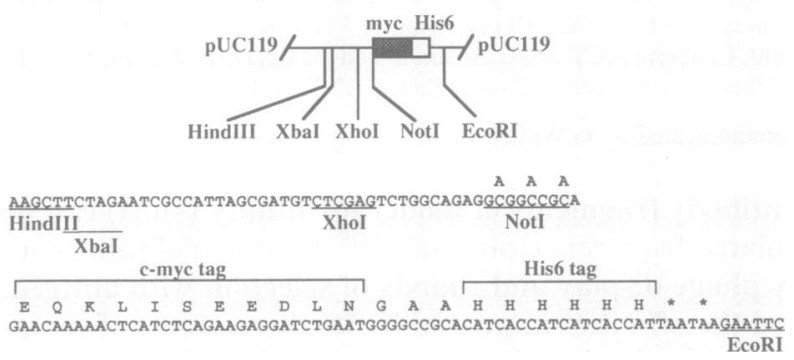

Fig. 2. Vectors. (A) The fd phage 'acceptor' vector fdDOG-2loxVkdel. Light chain genes $\left(V_{K}-C_{K}\right.$ and $\left.V_{\lambda}-C_{\lambda}\right)$ are cloned into this vector as ApaLI-AscI fragments. (B) The plasmid 'donor' vector pUC19-

2loxVHdel. Heavy chain variable region genes $\left(\mathrm{V}_{\mathrm{H}}\right.$ genes) are cloned into this vector as $\mathrm{NcoI}-\mathrm{XhoI}$ fragments. (C) The phagemid expression vector pUC119His6mycXba. Heavy and light chain genes encoding Fabs are cloned into this vector as $X b a \mathrm{I}-$ Not I fragments. Other features are marked as follows: sequences encoding $\mathrm{Lg} 3$, gene III leader sequence; LpelB, pelB leader sequence; $\mathrm{C} \kappa$, human kappa light chain constant region; $\mathrm{VH}$, heavy chain variable region; $\mathrm{CH} 1$, first heavy chain constant domain (human $\mathrm{C} \mu 1$ in fdDOG-2loxVkdel and human $C \gamma 1$ in pUC19-2loxVHdel); $\alpha$ TNF- $H$, the $V_{H}$ gene of the mouse anti-TNF $\alpha$ antibody mAb32 (Rathjen et al., 1992) linked to a human $\mathrm{C} \mu 1$ constant domain gene; gIII, fd phage gene III; loxP wt, wild-type loxP site (Hoess et al., 1982); loxP 511, a mutant loxP site with a single point mutation (Hoess et al., 1986); myc, peptide from cmyc recognized by the monoclonal antibody 9E10 (Munro and Pelham, 1986); His6, six histidines.

Materials and methods). As there are multiple copies of plasmid and phage replicons in each bacterial cell when Cre recombinase is delivered by phage P1 infection and at least 60 phage are produced per bacterium after overnight growth, we believe that each bacterium should yield at least one phage containing the heavy chain from the donor vector and therefore we estimate that the repertoire contained close to $6.5 \times 10^{10}$ different phage antibodies, with up to 60 copies of each.

\section{Specificity of selected antibodies}

The repertoire of phage was selected with a range of antigens, leading to isolation of binding specificities, as 


\begin{tabular}{|c|c|c|c|c|c|c|c|c|c|}
\hline \multirow{2}{*}{$\begin{array}{l}\text { Sample } \\
\text { Point }\end{array}$} & \multicolumn{7}{|c|}{ Total no. of colony forming units $\left(\times 10^{10}\right)$} & \multicolumn{2}{|l|}{ Significance } \\
\hline & $\begin{array}{l}\text { No } \\
\text { antibiotic }\end{array}$ & $a m p^{R}$ & $\operatorname{tet}^{R}$ & chlor $^{R}$ & $\operatorname{ampt}^{\mathrm{R}}+$ & $\begin{array}{l}\text { tet }^{R}+ \\
\text { chlor }^{R}\end{array}$ & $\begin{array}{l}\operatorname{amp}^{R}+ \\
\text { tet }^{R}+ \\
\text { chlor }^{R}\end{array}$ & & \\
\hline 1 & & 0.17 & & & & & & size of pUC19-2loxVHlib inoculum from frozen stock: & $1.7 \times 10^{9}$ \\
\hline 2 & 3.4 & 2.3 & & & & & & size of pUC19-2loxVHlib inoculum from overnight culture; & $2.3 \times 10^{10}$ \\
\hline \multirow[t]{2}{*}{3} & $65(\lambda)$ & & $10(\lambda)$ & & $19(\lambda)$ & & & no. of E.coli containing pUC19-2loxVHlib infected with fdDOG-2loxV $\lambda$ lib; & $1.9 \times 10^{11}(\lambda)$ \\
\hline & $73(\kappa)$ & & $11(\kappa)$ & & $8.0(\kappa)$ & & & no. of E.coli containing pUC19-2loxVHlib infected with fdDOG-2loxVklib; & $8.0 \times 10^{10}(\kappa)$ \\
\hline \multirow[t]{2}{*}{4} & $9.5(\lambda)$ & $22(\lambda)$ & $4.5(\lambda)$ & $6.0(\lambda)$ & $3.0(\lambda)$ & $2.0(\lambda)$ & $3.0(\lambda)$ & no. of E.coli containing pUC and fdDOG replicons co-infected with phage P1; & $3.0 \times 10^{10}(\lambda)$ \\
\hline & $29(\kappa)$ & $28(\kappa)$ & $7.5(\kappa)$ & $28(\kappa)$ & $3.0(\kappa)$ & $4.5(\mathrm{\kappa})$ & $3.5(\kappa)$ & & $3.5 \times 10^{10}(\kappa)$ \\
\hline 5 & & & & & & & & titre of fdDOG phage (t.u.) immediately after P1 infection and centrifugation; & $\begin{array}{l}9.9 \times 10^{9}(\lambda) \\
1.2 \times 10^{10}(\kappa)\end{array}$ \\
\hline \multirow[t]{2}{*}{6} & $31(\lambda)$ & & & & & & $16(\lambda)$ & no. of viable E.coli containing pUC. fdDOG and P1 replicons after $24 \mathrm{~h}$; & $1.6 \times 10^{11}(\lambda)$ \\
\hline & $35(\kappa)$ & & & & & & $9.5(\kappa)$ & & $9.5 \times 10^{10}(\kappa)$ \\
\hline 7 & & & & & & & & titre of fdDOG phage (t.u.) after $24 \mathrm{~h}$; & $\begin{array}{l}1.1 \times 10^{13}(\lambda) \\
3.0 \times 10^{13}(\kappa)\end{array}$ \\
\hline
\end{tabular}

Sample point. see Materials and methods: amp ${ }^{R}$. ampicillin resistant: tet ${ }^{R}$. tetracycline resistant: chlor $^{R}$. chloramphenicol resistant.

summarized in Table II. The repertoire was selected on all antigens and haptens by panning on antigen coated immunotubes; for the haptens NIP and fluorescein, the phage were also captured with biotinylated NIP-BSA and FITC-BSA and streptavidin-coated paramagnetic beads. To follow the selection process, E.coli were infected with the eluted phage after each round, and the phage screened for binding to antigen by ELISA, either as a 'polyclonal' population or as phage clones. DNA encoding the Fab fragments was amplified using the polymerase chain reaction from the population of phage after two to four rounds of selection and recloned into plasmid (Figure 2C) for expression of soluble Fab fragments.

We focused on the characterization of Fab fragments with specificities against the hapten-BSA conjugates of NIP (3-iodo-4-hydroxy-5-nitrophenyl-acetate) and FITC (fluorescein 5-isothiocyanate), as it would allow comparisons with the natural immune response to both haptens in mice, and facilitate the measurement of binding affinities to the free haptens (by fluorescence quench titrations). The fragments against hapten-BSA were first screened for binding to the free hapten by competition with fluorescein or NIP-caproic acid (NIP-CAP), or for binding to BSA. Most of the Fab fragments bound to hapten-BSA, but some also bound to BSA, or to free hapten.

We also characterized Fab fragments against four antigens of the kringle-serine protease family-hepatocyte growth factor/scatter factor (HGF/SF), plasmin, urokinasetype plasminogen activator (u-PA), and tissue-type plasminogen activator ( $\mathrm{t}-\mathrm{PA}$ ) - as members of a family of related proteins. Binding of 'polyclonal' phage was detected after three rounds of selection and proved to be specific, despite homologies between the members of this family (Figure 3). We also characterized Fab fragments against the mouse monoclonal antibody NQ11/7.22 (Griffiths et al., 1984), as the binding could be mapped to the variable regions, to the $\mathrm{Fc}$ region and to the remaining portions of the monoclonal antibody (Table III).

\section{Segment usage of selected heavy and light chains} The phage selected from the large $\left(6.5 \times 10^{10}\right.$ clones $)$ repertoire by binding to antigen were characterized by DNA sequencing. Many of the clones were different: 137
Table II. Binding specificities isolated from the library

\section{Haptens}

3-iodo-4-hydroxy-5-nitrophenyl-acetate (NIP)

Fluorescein

2-phenyloxazol-5-one (phOx)

$N$-(Carboxymethyl)-4-[(p-nitrobenzyloxyphosphoryl)-butyramide]

$N$-[2-hydroxy-3-(4-nitrophenyl)]-propyl-L-prolyl-glycine

Foreign antigens

Serum albumin (BSA) (bovine)

Tubulin (bovine)

Calmodulin (bovine)

Hepatocyte growth factor/scatter factor (HGF/SF) (murine)

Monoclonal antibody NQ11/7.22 (murine)

FixL (Bradyrhizobium japonicum)

Acetolactate synthase (ALS) (Brassica napus)

Lol pII (Lolium perenne)

Gene product of CDC4 (Schizosaccharomyces pombe)

Gene product of CDC8 (Schizosaccharomyces pombe)

Maltose binding protein (E.coli)

gp120 (HIV-1)

gp11 (T4 phage)

gp9 (T4 phage)

Human antigens

Tumour necrosis factor $\alpha$ (TNF $\alpha$ )

Thyroglobulin

High affinity $\operatorname{IgE}$ receptor (FceRI)

Tissue-type plasminogen activator (t-PA)

Urokinase-type plasminogen activator (u-PA)

Plasmin

Carcinoembryonic antigen (CEA)

c-erb B2

Tau40

Elongation factor $1 \alpha(\mathrm{EF}-1 \alpha)$

Calreticulin

Calnexin

Ferritin light chain

Factor VIII

UI snRNA

UlA protein

UIC protein

unique antigen-binding Fab fragments (with differing light or heavy chain protein sequences) were identified from a total of 215 clones sequenced (Table III). A range of $\mathrm{V}$ gene segments was seen: 17 of the $49 \mathrm{~V}_{\mathrm{H}}$ segments, 10 of the $26 \mathrm{~V}_{\kappa}$ segments and nine of the $21 \mathrm{~V}_{\lambda}$ segments 


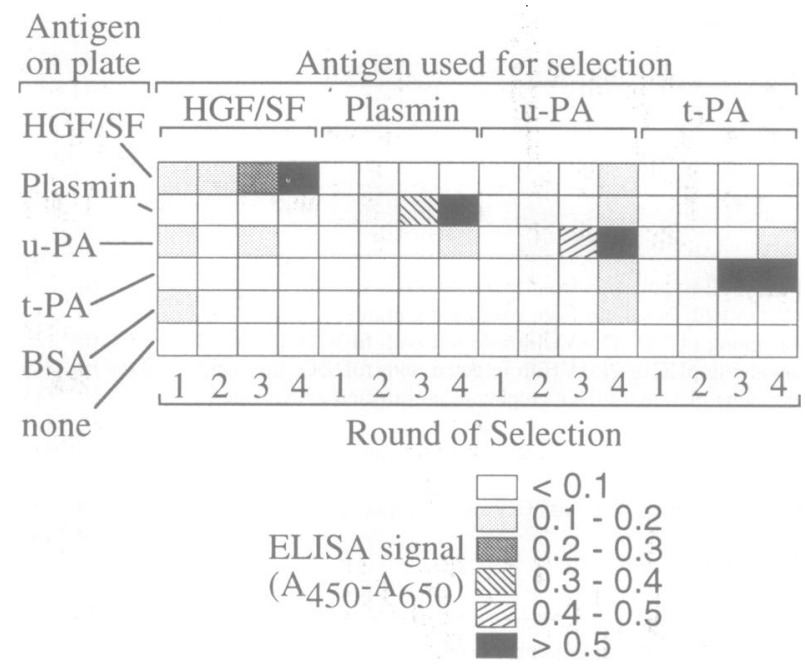

Fig. 3. Specificity of polyclonal phage against kringle serine protease family. 'Polyclonal' phage after one, two, three and four rounds of selection on either HGF/SF, plasmin, u-PA or t-PA, were assayed by ELISA for binding to the other members of the family, and to BSA. (see Figure 4). Each of the major heavy and light chain families were represented (Chuchana et al., 1990; Kabat et al., 1991; Williams and Winter, 1993), but not all the minor families. Thus $\mathrm{V}_{\mathrm{H}}$ segments were seen from families $1,3,4$ and 5 , but not 2 and $6 ; V_{\mathrm{K}}$ segments from subgroups $1,2,3$ and 4 , but not from 6 ; and $V_{\lambda}$ segments from families $1,2,3,7$ and 8 , but not 9 . The heavy chain $V_{H}$ segment DP-45 (included in the repertoire, but located on chromosome 16 outside the major locus on chromosome 14) was found in two Fab fragments (Table III and Figure 4A) binding to NIP-BSA.

Some $\mathrm{V}$ gene segments $\left(\mathrm{V}_{\mathrm{H}}\right.$ segments DP-7, DP-38, DP-47 and DP-67; $\mathrm{V}_{\mathrm{K}}$ segment DPK-15; and $\mathrm{V}_{\lambda}$ segment DPL-3) were seen frequently in the synthetic chains: of these only the $\mathrm{V}_{\mathrm{H}}$ segment DP-47 is common in natural antibodies. Conversely, some segments (like $V_{H}$ segments DP-63 and DP-71; $V_{K}$ segments DPK-1 and DPK-21; and $\mathrm{V}_{\lambda}$ segments DPL-5 and DPL-23) that are common in natural antibodies were not seen in the synthetic chains (Figure 4). Thus, except for DP-47, the pattern of usage of the segments from the synthetic repertoire, summed

Table III. CDR3 sequences and germline V gene segments from antigen-binding clones

\begin{tabular}{|c|c|c|c|c|c|c|c|c|c|c|}
\hline \multirow[t]{2}{*}{ Antigen $^{a}$} & \multirow[t]{2}{*}{ Clone } & \multicolumn{3}{|c|}{ Heavy chains ${ }^{b}$} & \multicolumn{3}{|c|}{ Light chains $^{c}$} & \multirow{2}{*}{$\begin{array}{l}\text { Selection } \\
\text { method }^{\mathrm{d}}\end{array}$} & \multirow[t]{2}{*}{ Round $^{e}$} & \multirow{2}{*}{$\begin{array}{l}\text { No. of } \\
\text { copies }^{f}\end{array}$} \\
\hline & & Family & Segment & CDR3' & Family & Segment & CDR3" & & & \\
\hline NIP-BSA & G09 & $\mathrm{VH} 3$ & DP-38 & AGTL & $\mathrm{V} \lambda 1$ & DPL-3 & AAWDDSLV & $\mathbf{M}$ & 4 & 1 \\
\hline NIP-BSA & E01 & VH3 & DP-38 & AGTL & $\mathrm{V \kappa} 2$ & DPK-12 & MQSIQLPT & $\mathbf{M}$ & $3 / 4$ & 2 \\
\hline NIP-BSA & G10 & VH3 & DP-38 & AGTL & Vк2 & DPK-12 & MQSIQLPAT & $\mathbf{M}$ & 4 & 1 \\
\hline NIP-BSA & G04 & $\mathrm{VH} 3$ & DP-38 & AGTL & $\mathrm{V} \lambda 1$ & DPL-3 & AAWDDGLSLV & $\mathbf{M}$ & 4 & 1 \\
\hline NIP-BSA & H08 & VH3 & DP-38 & AGTL & $\mathrm{V} \lambda 1$ & DPL-3 & AAWDDSLSGV & $\mathbf{M}$ & 4 & 1 \\
\hline NIP-BSA & G07 & VH3 & DP-38 & AGTL & $\mathrm{V} \lambda 3$ & DPL-16 & NSRDSSGSVRV & $\mathbf{M}$ & 4 & 1 \\
\hline NIP-BSA & $\mathrm{C} 09$ & VH3 & DP-38 & GGKD & $\mathrm{V} \lambda 7$ & DPL-18 & LLYYGGAYV & Im & 4 & 1 \\
\hline NIP-BSA & F03 & VHI & DP-10 & GGRL & $v \lambda 3$ & DPL-16 & NSRDSSGVSRV & $\mathbf{M}$ & 3 & 1 \\
\hline NIP-BSA & E07 & $\mathrm{VH} 3$ & DP-38 & GGTQ & $V \lambda 1$ & DPL-3 & AAWDDSLV & $\mathbf{M}$ & 3 & 1 \\
\hline NIP-BSA & H05 & VH3 & DP-38 & GGTQ & $V \lambda 1$ & DPL-3 & AAWDDSLPYV & $\mathbf{M}$ & 4 & 1 \\
\hline NIP-BSA & H03 & VH3 & DP-38 & HGQH & $\mathrm{V} \lambda \mathrm{I}$ & DPL-3 & AAWDDSLCPEFV & $\mathbf{M}$ & 4 & 1 \\
\hline NIP-BSA & H01 & VH3 & DP-38 & KGSE & $\mathrm{V} \lambda 1$ & DPL-3 & AAWDDSLAWFV & $\mathbf{M}$ & 4 & 1 \\
\hline NIP-BSA & $\mathrm{A} 12$ & VH3 & DP-47 & KGWS & $\mathrm{V} \lambda 1$ & DPL-4 & LAWDTSPRWV & $\mathrm{Im}$ & 3 & 1 \\
\hline NIP-BSA & Al0 & VH3 & DP-47 & KGWS & $\mathrm{V} \lambda 1$ & DPL-2 & TAWDDSLAVV & Im & 3 & 1 \\
\hline NIP-BSA & D08 & VH3 & DP-47 & KGWS & $\mathrm{V} \lambda 3$ & DPL-16 & NSRDSSGNHRV & $\mathrm{Im}$ & 4 & 1 \\
\hline NIP-BSA & G02 & VH3 & DP-49 & LGKA & Vк3 & DPK-22 & QQYGSSQRT & $\mathbf{M}$ & 4 & 1 \\
\hline NIP-BSA & E06 & VH3 & DP-38 & NGYF & $\mathrm{V} \lambda 1$ & DPL-3 & AAWDDSLRLV & $\mathbf{M}$ & 3 & 1 \\
\hline NIP-BSA & D03 & VH3 & DP-49 & PRGY & $\mathrm{V} \lambda \mathrm{l}$ & DPL-3 & AAWDDSLRLV & $\mathrm{Im}$ & 4 & 1 \\
\hline NIP-BSA & B02 & VH3 & DP-46 & MYMRS & $\mathrm{V} \kappa 2$ & DPK-18 & MQGTHWRPT & $\operatorname{Im}$ & 3 & 1 \\
\hline NIP-BSA & $\mathrm{E} 02$ & VH3 & DP-46 & MYRSV & $\mathrm{V \kappa} 2$ & DPK-18 & MQGKHWPLT & $\mathbf{M}$ & 3 & 1 \\
\hline NIP-BSA & A06 & VH3 & DP-42 & NGGHV & $\mathrm{V} \lambda \mathrm{l}$ & DPL-3 & AAWDDSLGF & Im & 3 & 1 \\
\hline NIP-BSA & D05 & VH3 & DP-47 & PAGSR & $\mathrm{V \kappa} 2$ & DPK-18 & MQGTHRRAT & $\mathrm{Im}$ & 4 & 1 \\
\hline NIP-BSA & A04 & VH3 & DP-38 & PATRS & $\mathrm{V \kappa 2}$ & DPK-15 & MQALQTPLT & $\mathrm{Im}$ & 3 & 1 \\
\hline NIP-BSA & F06 & VH3 & DP-47 & PFATF & $\mathrm{V \kappa 2}$ & DPK-18 & MRGTHRRAT & $\mathbf{M}$ & 3 & $i$ \\
\hline NIP-BSA & E08 & VH3 & DP-51 & PFLAH & $\mathrm{V} \kappa 2$ & DPK-18 & MQGTHWHPT & $\mathbf{M}$ & 3 & 1 \\
\hline NIP-BSA & $\mathrm{C} 05$ & VH3 & DP-32 & PLGAH & $\mathrm{V} \kappa 2$ & DPK-15 & MQALQSPT & Im & 4 & 1 \\
\hline NIP-BSA & E12 & VH3 & DP-47 & PMRGV & $\mathrm{V \kappa 2}$ & DPK-18 & MQGTHRRAT & $\mathbf{M}$ & 3 & 1 \\
\hline NIP-BSA & E05 & VH3 & DP-38 & PNGDQ & $\mathrm{V} \lambda 1$ & DPL-3 & AAWDDSLAFV & $\mathbf{M}$ & 3 & 1 \\
\hline NIP-BSA & E04 & VH3 & DP-38 & POTRR & Vк2 & DPK-15 & MQALQTPT & $\mathbf{M}$ & 3 & 1 \\
\hline NIP-BSA & A08 & VH3 & DP-47 & PRLPR & Vк1 & DPK-9 & QQSYSTRT & $\mathrm{Im}$ & 3 & 1 \\
\hline NIP-BSA & E10 & VH5 & DP-73 & PSGNV & Vк2 & DPK-19 & MQGTHWPFT & $\mathbf{M}$ & 3 & 1 \\
\hline NIP-BSA & A05 & VH1 & DP-25 & QGLRN & $\mathrm{V \kappa 2}$ & DPK-15 & MQALQTPLT & Im & 3 & 1 \\
\hline NIP-BSA & D06 & $\mathrm{VH} 3$ & DP-47 & RGHKA & Vк2 & DPK-18 & MQGTHWPAT & $\mathrm{Im}$ & 4 & 1 \\
\hline NIP-BSA & D02 & VH3 & DP-51 & SRGDS & $\mathrm{V} \lambda 1$ & DPL-3 & AAWDDSLRSV & $\mathrm{Im}$ & 4 & 1 \\
\hline NIP-BSA & F01 & VH3 & DP-47 & TFSPQ & Vк2 & DPK-18 & MQGTHRRAT & $\mathbf{M}$ & 3 & 1 \\
\hline NIP-BSA & B03 & VH3 & DP-47 & SFRRNL & $\mathrm{V} \lambda l$ & DPL-3 & AAWDDSLLV & $\mathrm{Im}$ & 3 & 1 \\
\hline NIP-BSA & A11 & VH3 & DP-58 & SFRRNL & $\mathrm{V} \times 3$ & DPL-16 & DSWDNSLVSPV & $\mathrm{Im}$ & 3 & 1 \\
\hline NIP-BSA & $\mathrm{CO4}$ & VH3 & DP-38 & PGYRGTR & $\mathrm{VK} 2$ & DPK-15 & MQALQSPT & $\operatorname{Im}$ & 4 & 2 \\
\hline NIP-BSA & D07 & VH3 & DP-38 & PGYRGTR & Vк2 & DPK-12 & MQSIQLPT & $\mathrm{Im}$ & 4 & 1 \\
\hline NIP-BSA & D01 & VH3 & DP-38 & PGYRGTR & Vk2 & DPK-15 & MQALQSPAT & Im & 4 & 1 \\
\hline NIP-BSA & $\mathrm{C} 10$ & VH3 & DP-38 & PGYRGTR & Vk2 & DPK-15 & MQALQTPVT & $\mathrm{Im}$ & 4 & 1 \\
\hline NIP-BSA & $\mathrm{C} 11$ & VH3 & DP-38 & PGYRGTR & $V \lambda 1$ & DPL-3 & AAWDDSLSAYV & $\mathrm{Im}$ & 4 & 1 \\
\hline NIP-BSA & F04 & VH3 & DP-45 & RAINGQR & $v \lambda 3$ & DPL-16 & NSRDSSGRVNV & $\mathbf{M}$ & 3 & 1 \\
\hline NIP-BSA & B04 & VH3 & DP-47 & RRGSTRY & VK2 & DPK-15 & MQALRTRT & $\mathrm{Im}$ & 3 & 1 \\
\hline NIP-BSA & F05 & VH3 & DP-38 & VNSRFAT & $\mathrm{V} \lambda 3$ & DPL-16 & NSRDSSGVSRV & $\mathbf{M}$ & 3 & 1 \\
\hline NIP-BSA & E11 & VH4 & DP-67 & IKFRSSSI & VK2 & DPK-19 & MQGTHWPFT & $\mathbf{M}$ & 3 & 1 \\
\hline NIP-BSA & H06 & VH4 & DP-67 & SFAKAFDY & $\mathrm{V} \lambda 1$ & DPL-3 & AAWDDSLPYV & $\mathrm{M}$ & 4 & $i$ \\
\hline
\end{tabular}


Table III. Continued

\begin{tabular}{|c|c|c|c|c|c|c|c|c|c|c|}
\hline \multirow[t]{2}{*}{ Antigen ${ }^{a}$} & \multirow[t]{2}{*}{ Clone } & \multicolumn{3}{|c|}{ Heavy chains ${ }^{\mathrm{h}}$} & Light $\mathrm{cl}$ & & & Selection & Round $^{\mathrm{e}}$ & No. of \\
\hline & & Family & Segment & CDR3 ${ }^{g}$ & Family & Segment & CDR3 $3^{g}$ & & & \\
\hline NIP-BSA & $\mathrm{E}(09$ & VH4 & DP-67 & SFAKAFDY & $\mathrm{V} \lambda 3$ & DPL-16 & NSRDSSGSVRV & $\mathbf{M}$ & 3 & 1 \\
\hline NIP-BSA & $\mathrm{C} 02$ & $\mathrm{VHI}$ & DP-7 & SKRTSFDY & $\mathrm{V} \kappa 2$ & DPK-18 & MQGTHWHPT & $\mathrm{Im}$ & 4 & 1 \\
\hline NIP-BSA & G08 & VH3 & DP-47 & SLFSKFDY & $v \lambda 3$ & DPL-16 & NSRDSSGVSRV & $\mathrm{M}$ & 4 & 1 \\
\hline NIP-BSA & A07 & VH3 & DP-47 & SVLSLFDY & $\mathrm{V} \lambda 1$ & DPL-3 & AAWDDSLFYPV & $\mathrm{Im}$ & 3 & 1 \\
\hline NIP-BSA & $\mathrm{CO} 3$ & VH3 & DP-45 & SYMRGMRN & $\mathrm{V} \lambda 3$ & DPL-16 & NSRDSSGNHRV & $\mathrm{Im}$ & 4 & 1 \\
\hline NIP-BSA & A02 & VH3 & DP-42 & HRRAYYMIP & $\mathrm{V \kappa} 2$ & DPK-18 & MQGTHWPVT & Im & 3 & 1 \\
\hline NIP-BSA & $\mathrm{A} 09$ & $\mathrm{VH} 4$ & DP-67 & IGKLSQPTS & $\mathrm{V} \kappa 2$ & DPK-18 & MQGTHWRPT & Im & 3 & 1 \\
\hline NIP-BSA & E03 & VH3 & DP-47 & RSGVRMLID & $\mathrm{V} \kappa 2$ & DPK-18 & MQGTHWRT & $\mathbf{M}$ & 3 & 1 \\
\hline NIP-BSA & $\mathrm{A} 03$ & VH3 & DP-42 & HLRWASGGPR & $V \kappa 2$ & DPK-18 & MQGTHWRT & $\mathrm{Im}$ & 3 & 1 \\
\hline NIP-BSA & G1I & VH3 & DP-47 & PLNSKKNTTTQ & $\mathrm{V} \lambda 1$ & DPL-3 & AAWDDSLFYV & $\mathbf{M}$ & 4 & 1 \\
\hline NIP-BSA & $\mathrm{C} 12$ & VH3 & DP-49 & GRTWSPSLPPLR & $V \kappa 2$ & DPK-12 & MQSIQLPLT & $\mathrm{Im}$ & 4 & 1 \\
\hline NQ11 (Fc) & NML7 & VH3 & DP-47 & KWGG & $\mathrm{V} \lambda 1$ & DPL-2 & AAWDDSLLGSV & $\mathrm{Im}$ & 2 & 1 \\
\hline NQII (Fc) & NML9 & $\mathrm{VHI}$ & DP-14 & GTGLDG & $\mathrm{V} \lambda 2$ & DPL-10 & CSYAGSSYV & $\mathrm{Im}$ & 2 & 1 \\
\hline NQ11 (Fc) & NML8 & VH3 & DP-47 & KFGNNM & $\mathrm{V} \lambda 3$ & DPK-23 & QQDYNLLT & $\mathrm{Im}$ & 2 & 1 \\
\hline NQ11 (Fv) & NMLI & VH3 & DP-47 & ASSPFVLQ & $\mathrm{V} \lambda 8$ & DPL-21 & VLYMGSGSAV & $\mathrm{Im}$ & $2 / 3 / 4$ & 25 \\
\hline NQ11 & NML3 & $\mathrm{VH} 1$ & DP-7/3g & YKSLSFDY & $\mathrm{V \kappa} 2$ & DPK-13 & MQRIEFPNT & $\mathrm{Im}$ & 2 & 1 \\
\hline NQ11 & NML5 & $\mathrm{VH} 1$ & DP-10 & AANYSKAHI & $V \lambda 1$ & DPL-2 & AAWDDSLACAV & Im & $2 / 3$ & 4 \\
\hline NQ11 (Fv) & NML2 & VH3 & DP-47 & RSWDGGMVD & $\mathrm{V} \kappa 1$ & DPK-5 & QQANSFRT & $\mathrm{Im}$ & 2 & 1 \\
\hline NQ11 (Fc) & NMLII & VH3 & DP-3 & SKLWVTFDY & $V \lambda I$ & DPL- $8 / 2^{\mathrm{g}}$ & AAWDDSLSRPV & $\mathrm{Im}$ & 3 & 1 \\
\hline NQ11 (Fc) & NML6 & VH3 & DP-3 & SKLWVTFDY & $V \lambda I$ & DPL-2 & AAWDDSLSRPV & $\mathrm{Im}$ & $2 / 3 / 4$ & 34 \\
\hline NQII & NML4 & VH3 & DP-3 & AKQSGVECLT & $\mathrm{V} \lambda 1$ & DPL-3 & AAWDDSLYNV & $\mathrm{Im}$ & 2 & 2 \\
\hline NQII (Fc) & NML10 & VH3 & DP-3 & SKYPLAWTLS & $v \lambda 1$ & DPL-2 & AAWDDSLNRNV & $\mathrm{Im}$ & 2 & 1 \\
\hline FITC-BSA & B01 & VH3 & DP-47 & ALRR & $V \kappa 2$ & DPK-15 & MQVLQTRT & $\mathrm{Im}$ & 3 & 1 \\
\hline FITC-BSA & B06 & VH3 & DP-47 & GGRV & $\mathrm{V \kappa} 2$ & DPK-15 & MQALQTRT & $\mathrm{Im}$ & 3 & 1 \\
\hline FITC-BSA & $\mathrm{A} 03$ & VH3 & DP-47 & IGQF & $V \lambda l$ & DPL-3 & AAWDDSLAFV & $\mathrm{Im}$ & $3 / 4$ & 4 \\
\hline FITC-BSA & DI0 & VH3 & DP-47 & KAKT & $\mathrm{V} \kappa 2$ & DPK-15 & MQALQTRT & $\mathrm{Im}$ & 4 & 1 \\
\hline FITC-BSA & G06 & VH3 & DP-47 & KSAI & $V \kappa 2$ & DPK- 15 & MQALQTRT & $\mathbf{M}$ & 4 & 1 \\
\hline FITC-BSA & $\mathrm{H} 03$ & VH3 & DP-47 & KSRW & $V_{\kappa l}$ & DPK-9 & QQSYSTRM & $\mathbf{M}$ & 4 & 1 \\
\hline FITC-BSA & $\mathrm{D} 12$ & VH3 & DP-47 & KSTV & Vк2 & DPK-15 & MQALRTRT & $\mathrm{Im}$ & 4 & 1 \\
\hline FITC-BSA & $\mathrm{A} 08$ & VH3 & DP-47 & LNRK & $V \kappa 2$ & DPK-15 & MQALQTRT & $\mathrm{Im}$ & $3 / 4$ & 4 \\
\hline FITC-BSA & D08 & VH3 & DP-47 & RHGS & $\mathrm{V} \kappa 2$ & DPK-15 & MQALRTRT & $\operatorname{Im}$ & 4 & 1 \\
\hline FITC-BSA & G07 & VH3 & DP-47 & RKRH & $V \kappa 2$ & DPK-15 & MQALQTLT & $\mathrm{M}$ & 4 & 1 \\
\hline FITC-BSA & H05 & VH3 & DP-47 & RSKT & $\mathrm{V} \kappa 2$ & DPK-15 & MQALQTRT & M & 4 & 1 \\
\hline FITC-BSA & $\mathrm{H}(\mathrm{)} 2$ & VH3 & DP-47 & RWSF & $v \lambda l$ & DPL-3 & AAWDDSLV & $\mathbf{M}$ & 4 & 1 \\
\hline FITC-BSA & E06 & VH3 & DP-47 & AKFRL & $\mathrm{V} \kappa 2$ & DPK-15 & MQALRTRT & $\mathrm{M}$ & 3 & 1 \\
\hline FITC-BSA & Ell & VH3 & DP-47 & AYHGR & $\mathrm{V} \kappa 2$ & DPK-15 & MQALQTRT & $\mathrm{M}$ & 3 & 1 \\
\hline FITC-BSA & $\mathrm{C} 02$ & VH3 & DP-47 & GKVLG & $V \kappa 2$ & DPK-15 & MQALQTPT & $\mathrm{Im}$ & 4 & 1 \\
\hline FITC-BSA & B02 & VH3 & DP-47 & GKVLG & $\mathrm{V} \kappa 2$ & DPK-15 & MRALQTPT & Im & $3 / 4$ & 2 \\
\hline FITC-BSA & E07 & VH3 & DP-47 & GSSRT & $v \lambda 1$ & DPL-3 & AAWDDSLPGYV & $\mathrm{M}$ & 3 & 1 \\
\hline FITC-BSA & E08 & VH3 & DP-47 & KRMDG & $V \kappa 2$ & DPK-15 & MQALQTRT & M & 3 & 1 \\
\hline FITC-BSA & Al0 & $\mathrm{VHI}$ & DP- 10 & LKRGH & $v \lambda l$ & DPL-3 & AAWDDSLGFV & $\mathrm{Im}$ & 3 & 1 \\
\hline FITC-BSA & D09 & VH3 & DP-47 & LRREY & $\mathrm{V} \kappa 2$ & DPK-15 & MQALRTRT & $\mathrm{Im}$ & 4 & 1 \\
\hline FITC-BSA & G12 & VH3 & DP-47 & RAGRD & $\mathrm{V} \lambda 1$ & DPL-3 & AAWDDSLFLV & $\mathrm{M}$ & 4 & 1 \\
\hline FITC-BSA & $\mathrm{DO} 3$ & VH3 & DP-47 & LKSAYK & $\mathrm{V} \kappa 2$ & DPK-15 & MQALQTPT & $\mathrm{Im}$ & 4 & 1 \\
\hline FITC-BSA & $\mathrm{C} 12$ & VH3 & DP-47 & LNVRPK & $\mathrm{V} \kappa 2$ & DPK-15 & MQALQTRT & $\mathrm{Im}$ & 4 & 1 \\
\hline FITC-BSA & B 10 & VH3 & DP-47 & SRGKSM & $\mathrm{V \kappa} 2$ & DPK-15 & MQALRTRT & $\mathrm{Im}$ & 3 & 1 \\
\hline FITC-BSA & E09 & VH3 & DP-47 & IRFRNAT & $\mathrm{V \kappa} 2$ & DPK-15 & MQALRTRT & $\mathbf{M}$ & 3 & 1 \\
\hline FITC-BSA & B09 & VH3 & DP-47 & LKTSTPV & $\mathrm{V \kappa} 2$ & DPK-15 & MRALQTPT & $\mathrm{Im}$ & $3 / 4$ & 2 \\
\hline FITC-BSA & G10 & VH3 & DP-47 & LSRAFTM & $\mathrm{V \kappa} 2$ & DPK-15 & MQALRTRT & $\mathbf{M}$ & 4 & 1 \\
\hline FITC-BSA & E03 & VH3 & DP-47 & LSRAFTM & $V \kappa 2$ & DPK-15 & MQALQTRT & $\mathbf{M}$ & 3 & 1 \\
\hline FITC-BSA & B07 & $\mathrm{VH} 4$ & DP-67 & AQRKYFDY & $\mathrm{V} \kappa 2$ & DPK-12 & MQSIQLRT & Im & 3 & 1 \\
\hline FITC-BSA & $\mathrm{D} 01$ & VH4 & DP-67 & DLRKHFDY & $\mathrm{V \kappa} 1$ & DPK-9 & QQSYSTRT & $\mathrm{Im}$ & 4 & 1 \\
\hline FITC-BSA & E10 & VH4 & DP-67 & DRWRVFDY & $\mathrm{V} \lambda 1$ & DPL-2 & AAWDDSLSIV & $\mathbf{M}$ & 3 & 1 \\
\hline FITC-BSA & A09 & $\mathrm{VH} 1$ & DP-14 & KGLRLFDY & $v \lambda 1$ & DPL-3 & AAWDDSLV & $\mathrm{Im}$ & 3 & 1 \\
\hline FITC-BSA & G08 & VH3 & DP-58 & KKYQSAAR & $\mathrm{V} \kappa 2$ & DPK-19 & MQGTHWPT & $\mathbf{M}$ & 4 & 1 \\
\hline FITC-BSA & B03 & VH4 & DP-67 & KTRRRFDY & $\mathrm{V} \kappa 2$ & DPK-15 & MQALHTRT & $\mathrm{Im}$ & 3 & 1 \\
\hline FITC-BSA & $\mathrm{C} 03$ & VH4 & DP-67 & KTRRRFDY & $\mathrm{V} \kappa 2$ & DPK-15 & MQALQTRT & $\mathrm{Im}$ & 4 & 1 \\
\hline FITC-BSA & G11 & VH3 & DP-47 & PYAKRFDY & $\mathrm{V} \kappa 2$ & DPK-15 & MQALQTRT & $\mathbf{M}$ & 4 & 1 \\
\hline FITC-BSA & G03 & VH3 & DP-47 & RFARSFDY & $v \lambda 3$ & DPL-16 & NSRDSSGSV & $\mathrm{M}$ & 4 & 3 \\
\hline FITC-BSA & A04 & VH4 & DP-67 & RSFVGYEI & $\mathrm{V} \lambda \mathrm{l}$ & DPL-3 & AAWDDSLV & $\mathrm{Im}$ & 3 & 2 \\
\hline FITC-BSA & D06 & VH4 & DP-67 & RWGRTFDY & $V_{\kappa} 2$ & DPK-15 & MQALQTRT & $\operatorname{Im}$ & 4 & 1 \\
\hline FITC-BSA & C06 & $\mathrm{VH} 1$ & DP-7 & SQKRLITG & $\mathrm{V} \kappa 2$ & DPK-15 & MQALQTRT & $\mathrm{Im}$ & 4 & 1 \\
\hline FITC-BSA & $\mathrm{C} 01$ & $\mathrm{VHI}$ & DP-7 & SQKRLITG & $\mathrm{V} \kappa 3$ & DPK-22 & QQYGSSPYT & $\mathrm{Im}$ & 4 & $i$ \\
\hline FITC-BSA & H04 & VH4 & DP-67 & SRKRAFDY & $V_{\kappa} 2$ & DPK-15 & MQALQTRT & $\mathrm{M}$ & 4 & 1 \\
\hline FITC-BSA & $\mathrm{C} 08$ & $\mathrm{VH} 4$ & DP-67 & SWVSGFDY & $\mathrm{V} \times 1$ & DPK-9 & QQSYSTRT & $\mathrm{Im}$ & 4 & 2 \\
\hline FITC-BSA & D04 & $\mathrm{VHI}$ & DP-7 & SYHRTFDY & $V_{\kappa l}$ & DPK-5 & QQANSFAAT & $\mathrm{Im}$ & 4 & 1 \\
\hline FITC-BSA & $\mathrm{C} 05$ & $\mathrm{VH} 1$ & DP-7 & SYHRTFDY & $V_{K 1}$ & DPK-5 & QQANSFPAT & $\mathrm{Im}$ & 4 & 1 \\
\hline FITC-BSA & D05 & $\mathrm{VHI}$ & DP-7 & THSKTFDY & $\mathrm{V} \lambda 8$ & DPL-21 & VLYMGSGVYV & $\mathrm{Im}$ & 4 & 1 \\
\hline FITC-BSA & $\mathrm{B} 12$ & $\mathrm{VH} 3$ & DP-47 & TRSSSYGE & $\mathrm{V} \kappa 2$ & DPK-15 & MQALRTRT & $\operatorname{Im}$ & 3 & 1 \\
\hline FITC-BSA & B04 & $\mathrm{VH} 4$ & DP-66 & WSRETNYS & $\mathrm{V} \lambda \mathrm{I}$ & DPL-3 & AAWDDSLWSAV & $\mathrm{Im}$ & 3 & 1 \\
\hline FITC-BSA & A07 & VH3 & DP-47 & RTRGALPRN & $\mathrm{V} \lambda 1$ & DPL-3 & AAWDDSLPRRLV & $\mathrm{Im}$ & 3 & 1 \\
\hline FITC-BSA & $\mathrm{A} 02$ & $\mathrm{VH} 3$ & DP-47 & YRFSAPPRD & $\mathrm{V} \lambda \mathrm{I}$ & DPL-3 & AAWDDSLPSGV & $\mathrm{Im}$ & 3 & 1 \\
\hline FITC-BSA & E04 & VH3 & DP-47 & RFNRLSPRRA & $\mathrm{V} \kappa 2$ & DPK-15 & MQALQTRT & $\mathrm{M}$ & 3 & 1 \\
\hline FITC-BSA & B05 & $\mathrm{VH} 1$ & DP-25 & SSVMGRVPVM & $\mathrm{V} \kappa 2$ & DPK- 15 & MQALQTLT & $\mathrm{Im}$ & 3 & 1 \\
\hline FITC-BSA & E05 & VH3 & DP -47 & TSGKLHSPRT & $\mathrm{V} \lambda 1$ & DPL-3 & AAWDDGLLRV & $\mathrm{M}$ & 3 & 1 \\
\hline FITC-BSA & D11 & VH5 & DP-73 & GRGRPSMAYDV & $\mathrm{V} \lambda 1$ & DPL-3 & AAWDDSLALV & Im & 4 & 1 \\
\hline FITC-BSA & B08 & VH3 & DP-47 & RSGVSRKVYTI & $\mathrm{V} \kappa 2$ & DPK-15 & MQALRTRT & $\mathrm{Im}$ & 3 & 1 \\
\hline Plasmin & $\mathrm{MPO}) 1$ & VH3 & DP-47 & MTPQFFDY & $\mathrm{V} \kappa 2$ & DPK-15 & MRALQTPT & $\mathrm{Im}$ & 4 & 1 \\
\hline Plasmin & $\mathrm{MPO} 2$ & $\mathrm{VH} 4$ & DP-67 & SAYSYFDY & $v \lambda 3$ & DPL-16 & NSRDSSGFQLV & $\mathrm{Im}$ & 4 & 1 \\
\hline
\end{tabular}


Table III. Continued

\begin{tabular}{|c|c|c|c|c|c|c|c|c|c|c|}
\hline \multirow[t]{2}{*}{ Antigen $^{a}$} & \multirow[t]{2}{*}{ Clone } & \multicolumn{3}{|c|}{ Heavy chains ${ }^{\mathrm{b}}$} & \multicolumn{3}{|c|}{ Light chains $^{c}$} & \multirow{2}{*}{$\begin{array}{l}\text { Selection } \\
\text { method }^{\mathrm{d}}\end{array}$} & \multirow[t]{2}{*}{ Round ${ }^{\mathrm{e}}$} & \multirow{2}{*}{$\begin{array}{l}\text { No. of } \\
\text { copies }\end{array}$} \\
\hline & & Family & Segment & $\mathrm{CDR}^{3 \mathrm{~g}}$ & Family & Segment & CDR3 $^{3}$ & & & \\
\hline$t-P A$ & MT09 & VH1 & DP-7 & DSGLGDPAL & $\mathrm{V} \lambda 2$ & DPL-11 & SSYTSSSTLV & $\operatorname{Im}$ & 4 & 1 \\
\hline $\mathrm{t}-\mathrm{PA}$ & MT03 & VH1 & DP-7 & DSGLGEPAL & $\mathrm{V} \lambda 2$ & DPL-11 & SSYTSSSTLG & Im & 4 & 1 \\
\hline $\mathrm{t}-\mathrm{PA}$ & MT06 & VHI & DP-7 & DSGLGEPAL & $v \lambda 2$ & DPL-11 & SSYTSSSTLV & $\mathrm{Im}$ & 4 & 1 \\
\hline t-PA & MT01 & VH1 & DP-7 & ESGLGDPAL & $\mathrm{V} \lambda 2$ & DPL-11 & SSYTSSSTLV & $\mathrm{Im}$ & 4 & 1 \\
\hline t-PA & MT07 & VH3 & DP-47 & TSRLKAHPS & $\mathrm{V} \lambda 1$ & DPL-8 & QSYDSNLRV & $\mathrm{Im}$ & 4 & $i$ \\
\hline u-PA & MU02 & VH3 & DP-47 & TSRLEAHPR & Vк2 & DPK-15 & MRALQTPT & $\mathrm{Im}$ & 4 & 1 \\
\hline $\mathrm{u}-\mathrm{PA}$ & MU01 & VH3 & DP-47 & TSRLKAHPS & Vкl & DPK-8 & QQLNSYPT & $\operatorname{Im}$ & 4 & 1 \\
\hline u-PA & MU03 & VH3 & DP-47 & TSRLKAHPS & $\mathrm{V} \lambda 3$ & DPL-16 & NSRDSSGFQLV & $\operatorname{Im}$ & 4 & 1 \\
\hline HGF/SF & MHI0 & VH3 & DP-47 & GRQSRL & Vкl & DPK-5 & QQANSFPIT & $\mathrm{Im}$ & 4 & 1 \\
\hline HGF/SF & MH19 & VH3 & DP-42 & KFPHFGD & Vкl & DPK-8 & QQLNSYPT & Im & 4 & 1 \\
\hline HGF/SF & MH22 & VH3 & DP-42 & KFPHFGD & Vк1 & DPK-5 & QQANSFPIT & Im & 4 & 4 \\
\hline
\end{tabular}

${ }^{a}$ The region of the monoclonal antibody NQ11/7.22 (NQ11) bound by the Fab is indicated (Fv or Fc region); three Fabs bound neither fragment and therefore probably interacted with the $\mathrm{CH} 1, \mathrm{CK}$ or hinge region. Hapten-BSA binding clones listed did not bind BSA alone.

${ }^{b}$ Human germline $\mathrm{V}_{\mathrm{H}}$ gene segments are assigned to families as in Tomlinson et al. (1992).

${ }^{c}$ Human germline $V_{K}$ gene segments (Cox et al., 1994) are assigned to subgroups as in Kabat et al. (1991) and human germline $V_{\lambda}$ gene segments (Williams and Winter, 1993) are assigned to families as in Chuchana et al. (1990).

${ }^{\mathrm{d}}$ Im, selected using antigen-coated immunotubes; $\mathbf{M}$, selected using biotinylated antigen and streptavidin-coated paramagnetic beads. Numbers refer to how many rounds of selection the library had undergone when Fabs with the sequence indicated were isolated.

'The number of independent clones which were isolated with the same sequence.

f CDR3 (complementarity determining region 3) for both heavy and light chains are as defined by Kabat et al. (1991).

gThese genes appear to have been created by cross-overs between two V genes during PCR amplification.
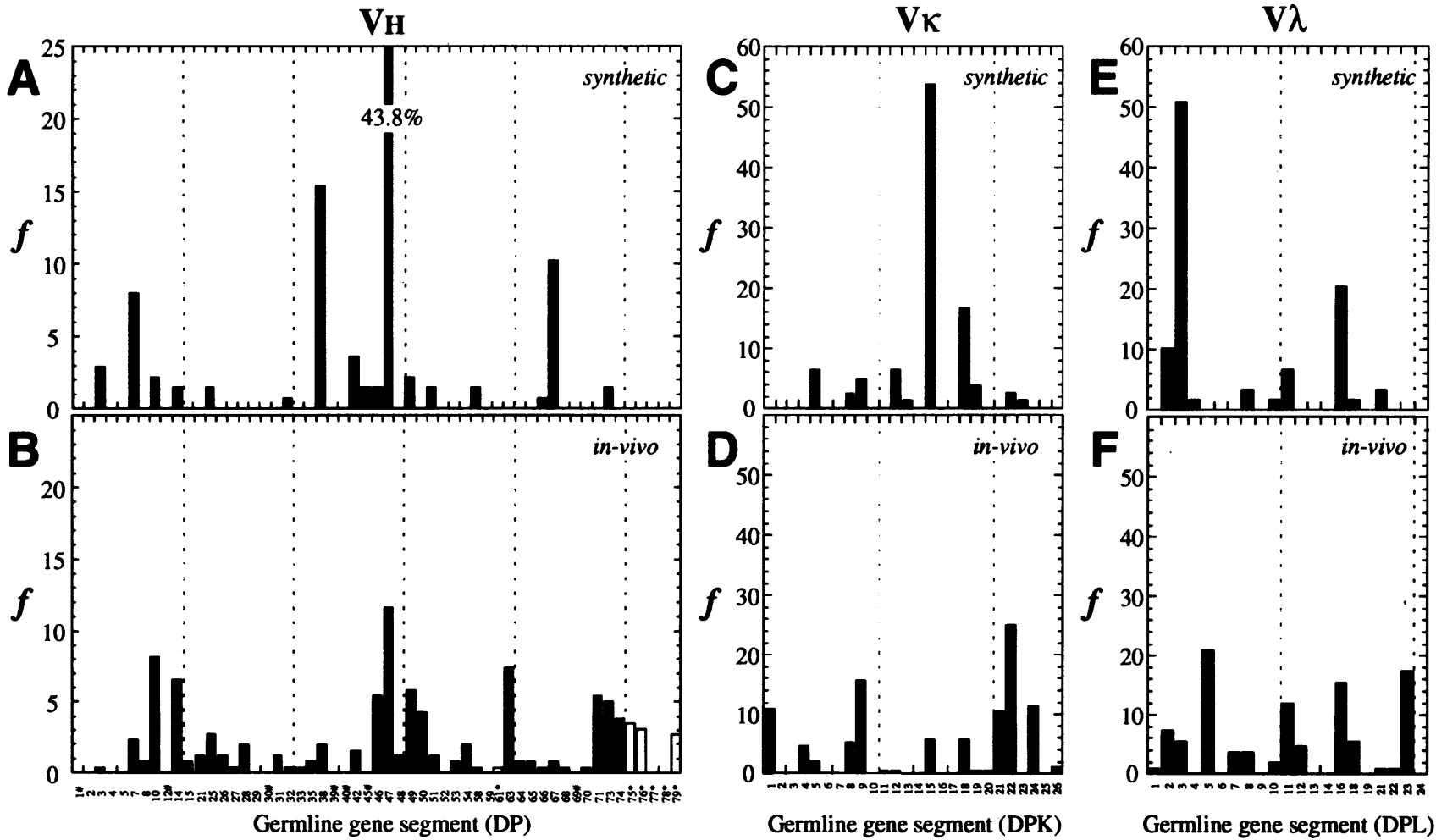

Germline gene segment (DPL)

Fig. 4. Use of human germline $V$ gene segments. Frequencies of use of human $V_{H}, V_{K}$ and $V_{\lambda}$ segments from the synthetic repertoire (A, $C$ and $E$ ), or from natural antibodies (B, D and F). Frequencies $(f)$ are plotted as \% of total. $\mathrm{V}$ gene usage was compiled for the synthetic antibodies from Table III, and for natural antibodies, from the 292 rearranged $V_{H}$ genes in the database described in Tomlinson et al. (1992), from the 236 rearranged $V_{\kappa}$ genes in the database described in Cox et al. (1994) and from a database of 110 rearranged $V_{\lambda}$ genes taken from the 'Entrez' sequence database (release 8.0; National Center for Biotechnological Information). $\mathrm{V}_{\mathrm{H}}$ segments are listed by DP numbers (Tomlinson et al., 1992), $V_{K}$ segments by DPK numbers (Cox et al., 1994) and $V_{\lambda}$ segments by DPL numbers (Williams and Winter, 1993). All V gene segments listed were included in the synthetic repertoire except those marked $(*) . \mathrm{V}_{\mathrm{H}}$ gene segments (located on chromosome 15 or 16) which are not used in vivo (Tomlinson et al., 1994), but which were included in the synthetic repertoire are indicated (\#).

over the limited number of antigens, appears to differ from the usage in vivo.

\section{Distribution of CDR3 lengths}

We also analysed the lengths and sequences of the CDR3 loops in the selected Fab fragments (Table III; Figure 5).
All the heavy chain CDR3 lengths included in the synthetic repertoire were present. The four residue loops almost all include a glycine residue, presumably to make the tight turn. However, the distribution of the heavy chain CDR3 lengths, biased towards short lengths, contrasts with natural antibodies. This appears to be especially characteristic of 


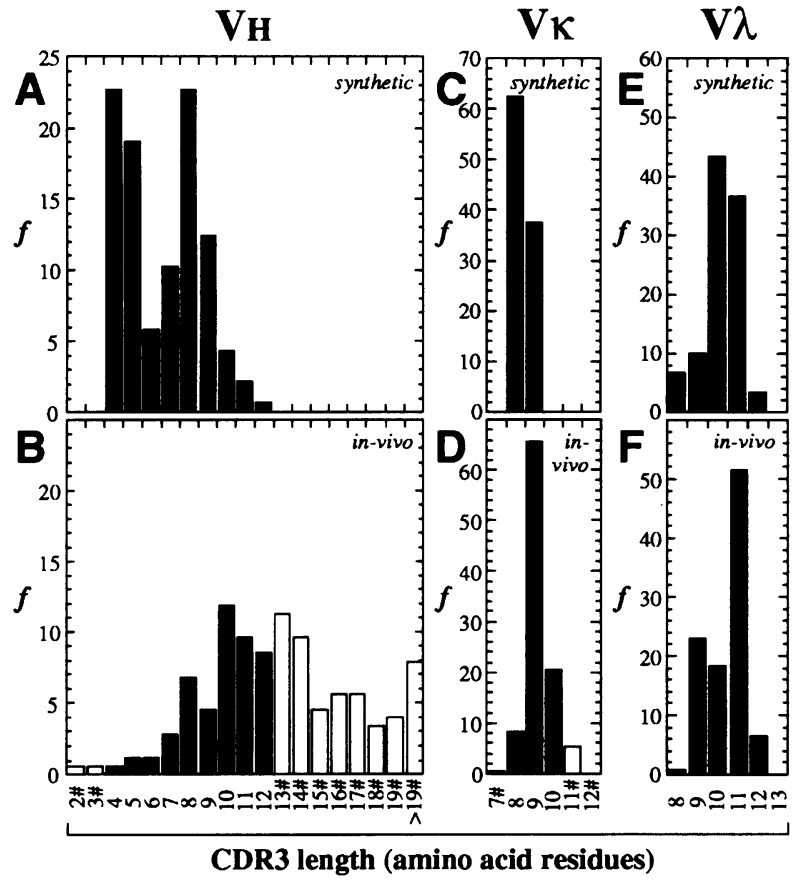

Fig. 5. Distribution of CDR3 lengths. Length distribution of CDR3 loops in human $V_{H}, V_{K}$ and $V_{\lambda}$ chains from the synthetic repertoire (A, C and E), or from natural antibodies (B, D and F). Frequencies $(f)$ are plotted as \% of total. Data were compiled as in Figure 4 legend, except that for natural rearranged $V_{H}$ genes the data was taken from the 177 human genes described by Wu et al. (1993). All CDR lengths listed were included in the synthetic repertoire except for those marked (\#)

the synthetic Fab fragments binding to hapten-BSA conjugates; those fragments binding to protein antigen appear to have longer CDR3 lengths. The distribution of CDR3 lengths for the synthetic $\lambda$ light chains was similar to natural antibodies, but differed for the $\kappa$ light chains, with no loops of 10 residues seen in the synthetic chains.

\section{Pairings of heavy and light chains}

The distribution of heavy and light chain pairings (Figure 6) identified some 52 different segment pairings among the 137 unique clones. Several $V_{H}$ gene segments were found paired with several $V_{\kappa}$ and $V_{\lambda}$ gene segments, for example DP-7, DP-38, DP-47 and DP-67 were each found in combination with several different light chain segments. Likewise, the light chain segments DPK-15 and DPL-3 were found in combination with several heavy chain segments. Not surprisingly these segments correspond to those used with higher frequency (see above). The usage of $\mathrm{V}$ gene segments differs for antibodies of different specificity, and the pattern of pairings provides a 'fingerprint', readily distinguishing the 'response' to different antigens. Some pairings, for example DP-47 with DPK15, and DP-47 with DPL-16, were also present in Fab fragments of different specificities.

There were also several examples of 'promiscuous' pairings (Clackson et al., 1991), chains that bind to the same antigen with any of several partner chains (Table III). For example, in the Fab fragments binding to NIP-BSA, the same heavy chain sequence (DP-38 segment with CDR3 of sequence AGTL) was paired with six different light chains of $\mathrm{V}_{\kappa} 2, \mathrm{~V}_{\lambda} 1$ and $\mathrm{V}_{\lambda} 3$ families (segments DPK-12, DPL-3 and DPL-16, respectively). Likewise in Fab fragments binding to FITC-BSA, the same light chain sequence (DPK-15 segment with CDR3 of sequence MQALQTRT) was paired with 15 different heavy chains of $\mathrm{V}_{\mathrm{H}} 1, \mathrm{~V}_{\mathrm{H}} 3$ and $\mathrm{V}_{\mathrm{H}} 4$ families (DP-7, DP47 and DP-67 segments, respectively).

\section{Affinities of selected antibodies}

Soluble Fab fragments were produced and purified via their hexahistidine tag by immobilized metal chelate affinity chromatography (IMAC), with typical yields of $100-500 \mu \mathrm{g} / \mathrm{l}$. From the large $\left(6.5 \times 10^{10}\right.$ clones $)$ repertoire we measured the affinities of several Fab fragments binding to soluble NIP-CAP or fluorescein by fluorescence quench titration (Eisen, 1964). The affinities $\left(K_{\mathrm{d}}\right)$ of the Fab fragments ranged from 3.8 to $217 \mathrm{nM}$ (Table IVA). This shows that high affinity anti-hapten antibodies can be isolated directly from large antibody repertoires. We also characterized three Fab fragments binding to the haptens NIP-CAP and fluorescein after selection of a small fraction $\left(10^{7}\right.$ clones) of the repertoire on NIP-BSA or FITC-BSA. In contrast these affinities $\left(K_{\mathrm{d}}\right)$ ranged from 0.8 to $12 \mu \mathrm{M}$ (Table IVB).

We measured kinetics and affinity of Fab fragments (from the $6.5 \times 10^{10}$ clone repertoire) binding to immobilized monoclonal antibody NQ11/7.22 and HGF/SF by surface plasmon resonance (Table IVA). For the Fab fragments against the variable region (NML1) and the Fc portion (NML9) of antibody NQ11/7.22, the binding affinities were determined both by on- and off-rate analysis and by Scatchard plots of equilibrium binding (see Figure 7) to be in the range $30-60 \mathrm{nM}$. For NML1, the on-rate was calculated as $6.4 \times 10^{5} \mathrm{M}^{-1} \mathrm{~s}^{-1}$ and the offrate as $2.2 \times 10^{-2} \mathrm{~s}^{-1}$; for NML9 as $5.2 \times 10^{5} \mathrm{M}^{-1} \mathrm{~s}^{-1}$ and $3 \times 10^{-2} \mathrm{~s}^{-1}$, respectively. However for the Fab fragment (MH22) against HGF/SF, Scatchard analysis indicated several classes of binding sites, with affinities from micro- to nanomolar. At low Fab concentrations $(<40 \mathrm{nM})$, where high affinity interactions predominate, the affinity could be estimated as $7 \mathrm{nM}$ from an initial onrate of $1.7-1.9 \times 10^{6} \mathrm{M}^{-1} \mathrm{~s}^{-1}$ and off-rate of $1.3 \times 10^{-2} \mathrm{~s}^{-1}$.

\section{Discussion}

In the immune system, antibodies with moderate affinities are selected from primary repertoires, and their affinities improved step-wise by rounds of somatic mutation and selection. However, theoretical arguments based on the idea of 'shape space' have suggested that larger and more diverse repertoires should give rise to higher affinity antibodies (Perelson and Oster, 1979). The probability $(P)$ that an epitope is recognized by at least one antibody in a repertoire depends on the probability $(p)$ that an antibody recognizes a random epitope with an affinity above a threshold value, and on the number of antibodies $(N)$ according to the equation $P=1-\mathrm{e}^{-N p}$ (Perelson and Oster, 1979). This predicts, as expected, that the larger the repertoire, the greater the chances of finding a high affinity antibody. However it does not provide an explicit relationship between repertoire size and affinity.

Here we used a repertoire of phage antibodies as an 'artificial immune system' to explore the possibility of 


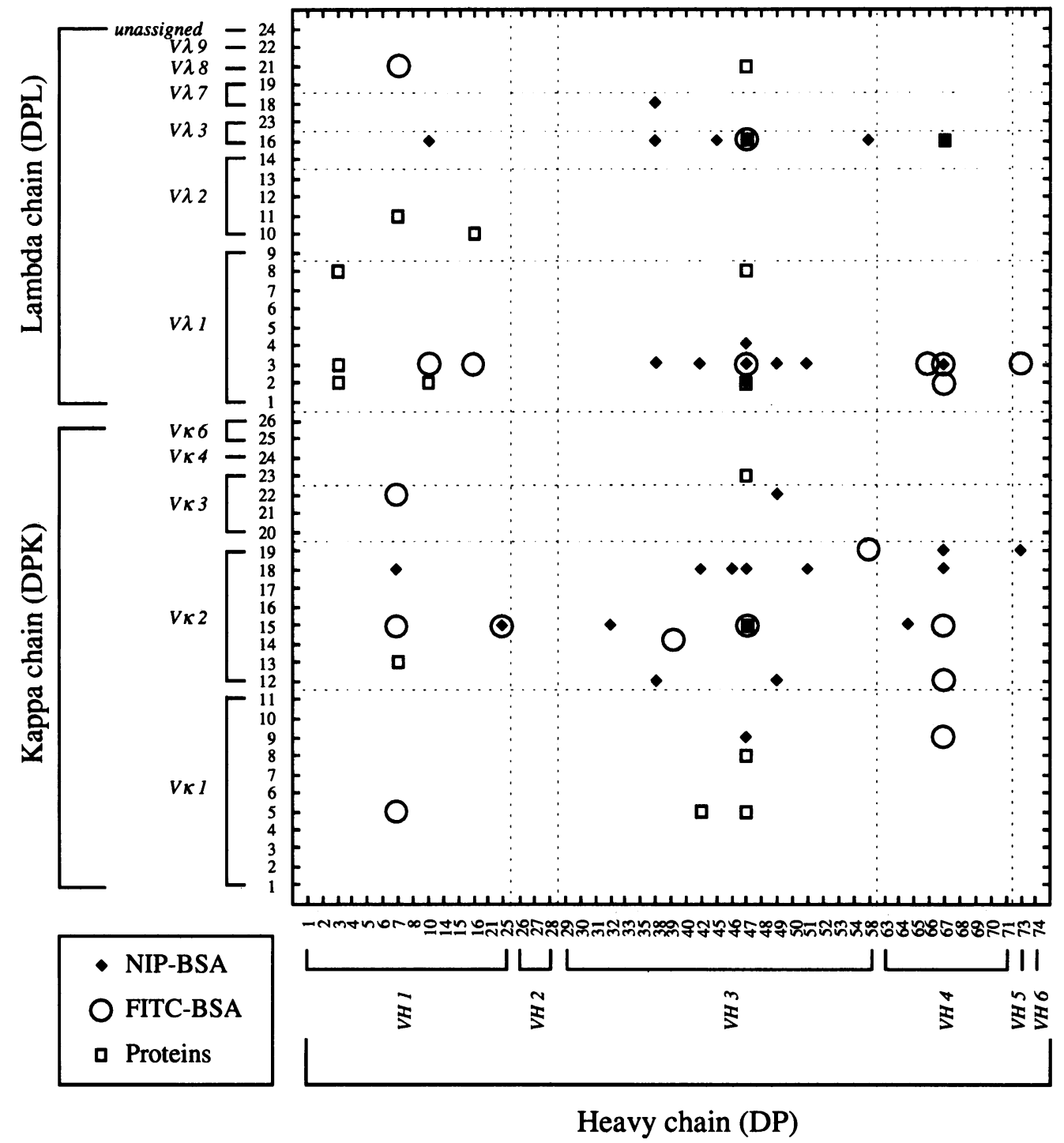

Fig. 6. Pairings of heavy and light chain $\mathrm{V}$ gene segments in the synthetic repertoire. Data were compiled and are listed as described in Figure 4 legend. Fab fragments binding NIP-BSA are indicated by black diamonds; Fab fragments binding FITC-BSA by open circles; and Fab fragments binding antibody NQ11/7.22, plasmin, u-PA, t-PA or HGF/SF by open squares.

isolating high affinity antibodies directly from a very large primary antibody repertoire. Previously the size of phage antibody repertoires has been limited to $<10^{9}$ clones by the efficiency of transfection of DNA into bacteria: here we have used the process of combinatorial infection and in vivo recombination (Waterhouse et al., 1993) to overcome this. Bacteria harbouring a repertoire of heavy chains (encoded on a plasmid replicon) were infected with phage encoding a repertoire of light chains, and the heavy chain genes translocated to the phage replicon by recombination within the bacterium. By this means we were able to make a repertoire of $6.5 \times 10^{10}$ clones and obtained antibodies to a range of antigens and haptens (Table II) with affinities $<10 \mathrm{nM}$ (Table IVA). With a smaller repertoire $\left(10^{7}\right.$ clones) we only found antibodies of moderate affinities $(>800 \mathrm{nM})$, in agreement with earlier work in which antibody fragments isolated from smaller repertoires $\left(10^{7}-10^{8}\right.$ clones) were found to have affinities of $700 \mathrm{nM}$ for the hapten NIP (Hoogenboom and Winter, 1992) and $140 \mathrm{nM}$ for the hapten fluorescein
(Barbas et al., 1992c, 1993). The characterization of repertoires of different sizes (and of known diversity) should help in defining the explicit relation between repertoire size and affinity.

As shown in Figure 8, the binding affinities of secondary response (hypermutated) mouse monoclonal antibodies to the haptens NIP and fluorescein were similar to those of human Fab fragments isolated directly from the large repertoire. Only a single mouse anti-NIP antibody has been described (Lucisano-Valim and Lachmann, 1991) with an affinity $\left(K_{\mathrm{d}}=5.6 \mathrm{nM}\right)$ similar to the best human Fab fragment $\left(K_{\mathrm{d}}=4.0 \mathrm{nM}\right.$; Table IVA). However, eight mouse monoclonal antibodies have been described with higher affinities for fluorescein than the best human Fab fragment $\left(K_{\mathrm{d}}=3.8 \mathrm{nM}\right.$; Table IVA), the best of these (4-4-20) with an affinity of $0.19 \mathrm{nM}$ (Bedzyk et al., 1986).

It is quite possible that antibody fragments with even higher affinities are present in the repertoire, as we had designed the selection process to capture antibody fragments with a range of binding affinities to antigen, 
Table IV. Sequences and affinities of Fab fragments

(A) Fabs from $6.5 \times 10^{10}$ repertoire

\begin{tabular}{|c|c|c|c|c|c|c|}
\hline \multirow[t]{2}{*}{ Antigen } & \multirow[t]{2}{*}{ Clone } & \multicolumn{2}{|c|}{ Heavy chain } & \multicolumn{2}{|c|}{ Light chain } & \multirow[t]{2}{*}{$K_{\mathrm{d}}(\mathrm{nM})$} \\
\hline & & segment & CDR3 & segment & CDR3 & \\
\hline $\mathrm{NIP}-\mathrm{CAP}$ & NIP-G6 & DP-38 & AGTL & DPK-12 & MQSIQLPT & $4.0( \pm 0.1)$ \\
\hline NIP-CAP & NIP-G $10^{c}$ & DP-38 & AGTL & DPK-12 & MQSIQLPAT & $5.4( \pm 0.2)$ \\
\hline NIP-CAP & $\mathrm{NIP}-\mathrm{HI} \mathrm{I}^{\mathrm{C}}$ & DP-38 & KGSE & DPL-3 & AAWDDSLAWFV & $11.3( \pm 0.4)$ \\
\hline NIP-CAP & NIP-C11 & DP-38 & PGYRGTR & DPL-3 & AAWDDSLSAYV & $16.5( \pm 0.5)$ \\
\hline NIP-CAP & NIP-H3 $3^{c}$ & DP-38 & $\mathrm{HGQH}$ & DPL-3 & AAWDDSLCPEFV & $19.7( \pm 1.7)$ \\
\hline NIP-CAP & NIP-G $11^{\circ}$ & DP-47 & PLNSKKNTTTQ & DPL-3 & AAWDDSLFYV & $20.1( \pm 3.6)$ \\
\hline NIP-CAP & NIP-G9 ${ }^{c}$ & DP-38 & AGTL & DPL-3 & AAWDDSLV & $22.0( \pm 1.0)$ \\
\hline NIP-CAP & NIP-E5 ${ }^{c}$ & DP-38 & PNGDQ & DPL-3 & AAWDDSLAFV & $22.1( \pm 0.8)$ \\
\hline NIP-CAP & NIP-E7c & DP-38 & GGTQ & DPL-3 & AAWDDSLV & $29.8( \pm 1.1)$ \\
\hline NIP-CAP & NIP-A4 & DP-38 & PATRS & DPK-15 & MQALQTPLT & $48( \pm 1.0)$ \\
\hline NIP-CAP & NIP-C9 & DP-38 & GGKD & DPL-18 & LLYYGGAYV & $59( \pm 3.0)$ \\
\hline Fluorescein & FITC-B4 & DP-66 & WSRETNYS & DPL-3 & AAWDDSLWSAV & $3.8( \pm 0.4)$ \\
\hline Fluorescein & FITC-A4 & DP-67 & RSFVGYEI & DPL-3 & AAWDDSLV & $14.3( \pm 2.0)$ \\
\hline Fluorescein & FITC-B11 & DP-47 & IGQF & DPL-3 & AAWDDSLAFV & $24.1( \pm 0.8)$ \\
\hline Fluorescein & FITC-B7 & DP-67 & AQRKYFDY & DPK-12 & MQSIQLRT & $151( \pm 3.0)$ \\
\hline Fluorescein & FITC-A2 & DP-47 & YRFSAPPRD & DPL-3 & AAWDDSLPSGV & $217( \pm 16.0)$ \\
\hline NQ11 (Fv) & NML1 & DP-47 & ASSPFVLQ & DPL-21 & VLYMGSGSAV & $32^{\mathrm{a}}$ and $34^{\mathrm{b}}$ \\
\hline NQ11 (Fc) & NML9 & DP-14 & GTGLDG & DPL-10 & CSYAGSSYV & $41^{\mathrm{a}}$ and $58^{\mathrm{b}}$ \\
\hline $\mathrm{HGF} / \mathrm{SF}$ & MH22 & DP-42 & KFPHFGD & DPK-5 & QQANSFPIT & $7^{\mathrm{b}}$ \\
\hline \multicolumn{7}{|c|}{ (B) Fabs from $1 \times 10^{7}$ repertoire } \\
\hline \multirow[t]{2}{*}{ Antigen } & \multirow[t]{2}{*}{ Clone } & \multicolumn{2}{|c|}{ Heavy chain } & \multicolumn{2}{|c|}{ Light chain } & \multirow[t]{2}{*}{$K_{\mathrm{d}}(\mu \mathrm{M})$} \\
\hline & & segment & CDR3 & segment & CDR3 & \\
\hline NIP-CAP & sNIP-D10 & DP-53 & PWARGTD & DPK-21 & QQYNNWLST & $8( \pm 0.6)$ \\
\hline NIP-CAP & sNIP-F3c & DP-47 & NYNAAFDY & DPL-21 & VLYMGSGHRV & $12( \pm 1.3)$ \\
\hline Fluorescein & sFITC-C2 & DP-67 & SGVRGLMT & DPK-9 & QQSYSTRT & $0.82( \pm 0.14)$ \\
\hline
\end{tabular}

Affinities $\left(K_{\mathrm{d}}\right)$ for haptens were determined by fluorescence quench titration. Affinities $\left(K_{\mathrm{d}}\right)$ for protein antigens were determined by SPR, by Scatchard analysis ${ }^{\mathrm{a}}$ and from analysis of the rate constants ${ }^{\mathrm{b}}$. All clones were derived from selections on immunotubes except for those marked ${ }^{\mathrm{c}}$ which were derived from selections using magnetic beads. The residues in the light chain CDR3 regions encoded by randomized codons are in bold.

including those with only moderate affinity. Thus, we took advantage of the binding avidity of multiple Fab fragments on the surface of the phage (by using phage rather than phagemid vectors) and short wash times to retain phage with fast dissociation kinetics. Also for selections on immunotubes we used a high coating density of antigen to favour rebinding of the phage, and for selections with soluble biotinylated antigen we used a relatively high concentration of antigen ( $50 \mathrm{nM})$ to try to include even those phage with moderate equilibrium constants (Hawkins et al., 1992). Presumably it would be possible to favour the selection of higher affinity antibodies from this repertoire by more stringent selection.

The phage repertoire was not only large, but also highly diverse. It was assembled from the majority of $\mathrm{V}$ gene segments used in vivo, including all the major $\mathrm{V}_{\mathrm{H}}$ and $\mathrm{V}_{\lambda}$ families, and $V_{K}$ subgroups. The segments included all the major heavy and light chain CDR1 and CDR2 loop conformations (Chothia and Lesk, 1987; Chothia et al., 1989, 1992), and the CDR3 loops were made of diverse sequences and lengths. The chains were paired at random (Huse et al., 1989), creating diverse pairings. The repertoire was sufficiently large that several pairings of a single heavy or light chain could be isolated from the repertoire. Such chain 'promiscuity' is characteristic of repertoires derived from the mRNA from immune sources (see for

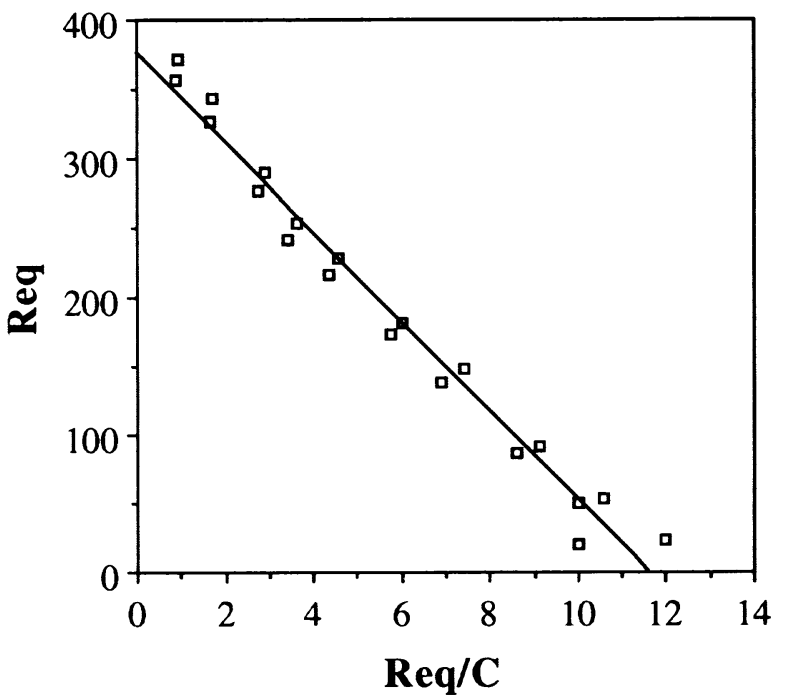

Fig. 7. Affinity of Fab NMLl by SPR. Binding of the Fab to a sensor chip surface coated with mouse monoclonal antibody NQ11/7.22. See Materials and methods for further details. For each concentration of antibody $(\mathrm{C}, \mathrm{nM})$, the equilibrium binding signal (Req, in resonance units) was plotted against the Req/C. The slope gives the binding affinity $\left(K_{\mathrm{d}}\right)$ as $32.3 \mathrm{nM}$. 

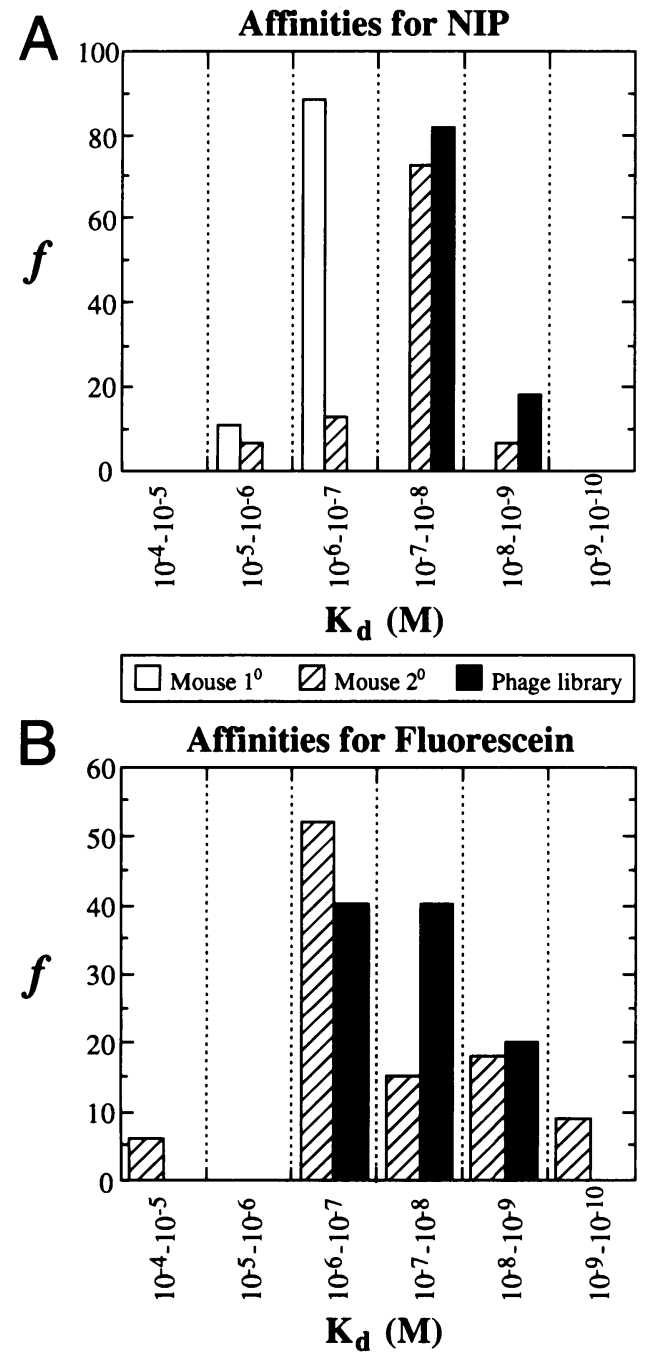

Fig. 8. Affinities for synthetic antibodies and mouse monoclonal antibodies. Affinity data for the Fab fragments from the synthetic repertoire were compiled from Table IVA. (A) Antibodies binding to NIP; data on the mouse immune response were taken from Mariuzza and Strand (1981), Cumano and Rajewsky (1986) and Lucisano-Valim and Lachmann (1991). (B) Antibodies binding fluorescein; data on the mouse immune response were taken from Kranz and Voss (1981), Kranz et al. (1982), Reinitz and Voss (1984), Bates et al. (1985), Bedzyk et al. (1986) and Denzin and Voss (1992).

example Clackson et al., 1991) and reflects the chances of a chain making multiple pairings, which in turn depends on the frequency of the chain and the size of the repertoire.

In the antibodies binding to the haptens, the combinations of heavy and light chain segments appeared to be restricted. For example, the antibodies binding to soluble hapten NIP-CAP (Table IVA) mainly utilized the heavy chain segment DP-38 and the light chain segment DPL3 , and included a four residue heavy chain CDR3 loop with a distinctive motif, X-Gly-X-X. This is reminiscent of the restricted response seen with mouse antibodies raised by immunization with the hapten 4-hydroxy-3nitrophenyl acetate (NP): the immune response in C57BL/ 6 mice is dominated by antibodies with $\lambda 1$ light chains paired with heavy chains encoded by the $\mathrm{V} 186.2 \mathrm{~V}_{\mathrm{H}}$ segment and the DFl16.1 D segment (Bothwell et al., 1981; Cumano and Rajewsky, 1985).
As in vivo, only a few segments contributed to most of the 'response'. However, the usage of $\mathrm{V}$ gene segments found in the selected Fab fragments from the artificial repertoire differed from that of antibodies from natural repertoires (Figure 4). This might reflect a different representation of segments in the primary repertoire, or the high frequency of sequences from phage antibodies directed against hapten conjugates. Nevertheless we would expect the artificial repertoire to be shaped by different selection pressures to those that operate in vivo, leading to a different spectrum of binding sites. If 'holes' exist in the natural repertoire, they may be absent in an artificial repertoire and vice versa. Despite the differences in segment usage between the natural and synthetic antibodies, there is one striking similarity: the heavy chain segment DP-47 is the most commonly used segment in both. In vivo, it has been suggested that pre-B cells displaying DP-47 heavy chains are selected by binding to autoantigen (Schwartz and Stollar, 1994). We suggest that the usage of DP-47 reflects a more fundamental property of this segment; the structure of the binding site may be more capable of accommodating a wider diversity of antigens than other segments (Figure 6).

We conclude that human antibodies with affinities in the nanomolar range, and specific for protein antigens and haptens, can be derived directly from large and diverse synthetic phage antibody repertoires. The binding affinities are typical of somatically mutated mouse antibodies produced in vivo, and presumably could be improved further through rounds of 'chain shuffling' (Marks et al., 1992b) or point mutagenesis (Hawkins et al., 1992) to create binding specificities and affinities outside the reach of the immune system. In addition, the use of synthetic phage antibody repertoires based on $\mathrm{V}$ gene segments to simulate natural immune systems may provide further insights into immune strategy, for example in helping to define the relationship between affinity and repertoire size, or the relationship between the structures of the antigen binding sites and the usage of V, D and J segments, CDR3 lengths and junctional diversity.

\section{Materials and methods}

\section{Vectors}

The 'acceptor' vector, into which light chain repertoires are cloned, fdDOG-2lox Vkdel, is identical to fdDOG-2lox (Waterhouse et al., 1993), except that the light chain variable region gene has been deleted (Figure $2 \mathrm{~A})$. The 'donor' vector, into which heavy chain repertoires are cloned, pUC19-2loxVHdel, is identical to pUC19-2lox (Waterhouse et al., 1993), except that the heavy chain variable region gene has been deleted (Figure 2B). The vector for expression of soluble Fab fragments, pUC119His6mycXba, is a derivative of pUC119 (Vieira and Messing, 1987) in which the polylinker has been replaced by the sequence shown in Figure 2C.

\section{Construction of synthetic heavy chain repertoires}

A diverse repertoire of rearranged $V_{H}$ genes has previously been built in vitro (Nissim et al., 1994) from a bank of 49 cloned $V_{H}$ gene segments (Tomlinson et al., 1992) [one of the 50 segments (DP-20) included in the repertoire of Nissim et al. (1994) was a pseudogene]. To these segments completely randomized CDR3 regions (Kabat et al., 1991) were appended, varying in size between four and 12 residues (Figure 1A). This cloned repertoire, with $>10^{8}$ different clones, was re-amplified using PCR with primers pUC-reverse and JH-Xho-FOR (Table VA), the DNA was cut with $N c o I$ and $X h o l$, and ligated into pUC19-2lox VHdel. The ligation mixture was electroporated (Dower et al., 1988) into E.coli 
Table V. Oligonucleotides

A. Re-cloning of synthetic human $\mathrm{VH}$ repertoires into pUC19-2lox VHdel

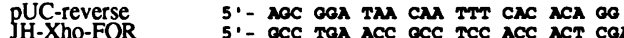

B. Construction of synthetic human kappa chain repertoires

1. Amplification of human $\mathrm{CK}$

CKFOR 5'- CTE CTA TTA TCE OEC OCE CCT TTA TTA ACA CTC TCC CCT OTT OMA OCT CTT TET GAC OOC

2. Human VK back primers

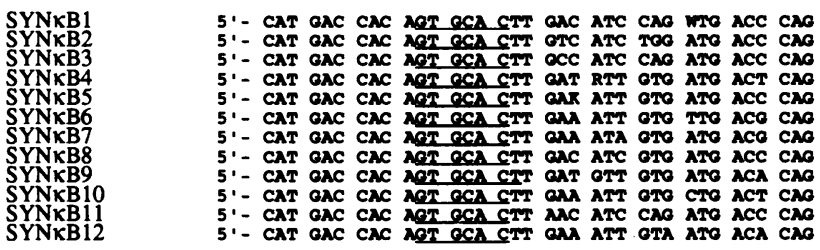

DPK1,4,5,6,7,8,9,11

DPK3

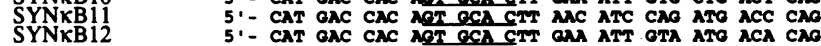

3. Human VK forward primers encoding synthetic CDR3s

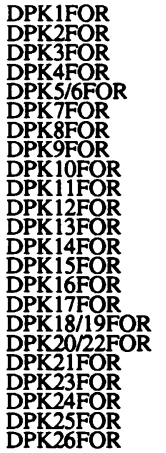

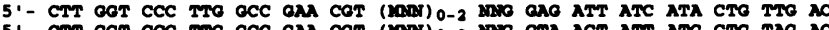
5: - CTT OOT CCC TTE OCC OAM COT (MODS) 0-2 MDNO OTA ACT ATT ATE CTE TAC AC

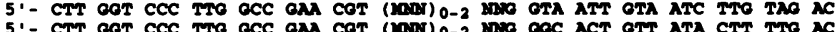

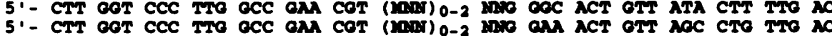

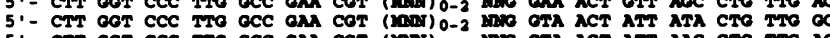

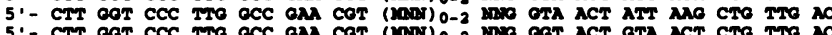

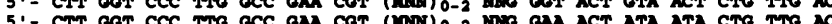

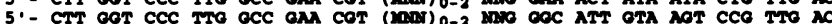

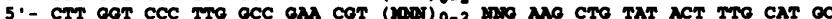

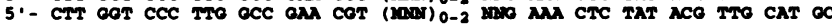

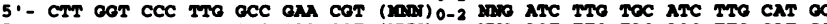
5: - CTT GOT CCC TTE OCC OMA CGT (DODS) 0-2 ADNO AOT TTC TAC AOC TTC CAT OC 5: - CTT OOT CCC TTE OCC OMM COT (MONS 0-2 BDS MMA TTE TOT MOC TTO CAT OC

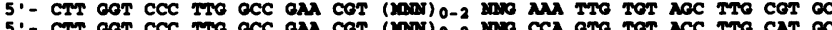
5. - CTI OOT CCC TTO OCC GAM COT

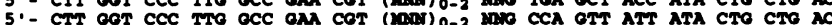

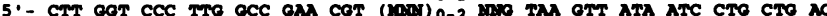

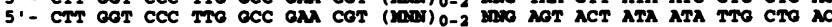

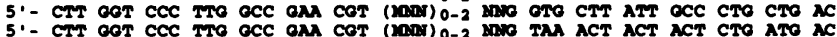

1. Amplification of human $\mathrm{C} \lambda 2$

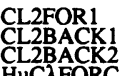

\section{5:- OCA ATY COO OOT GAG GOT TOA GNA}

5:- CCC CCA ACC TTC TEC CCC TCA TCC

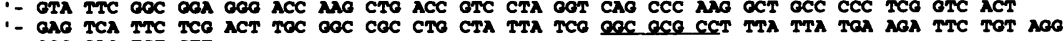

2. Human $\mathrm{V} \lambda$ back primers

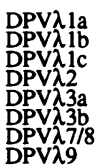

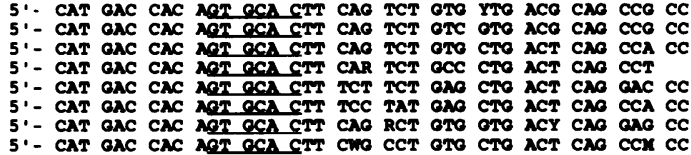

3. Human $V \lambda$ forward primers encoding synthetic CDR3s

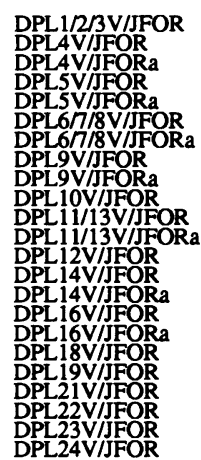

5:- CTT OOT CCC TCC OCC GM TAC (nON) 0-5 -.- CAO OCT OTC ATC CCA TOC TOC ACA OTA

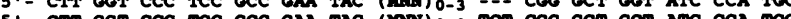
5. - CTT OOT CCC TCC OCC GM TAC (ama) 0-2 TCS CGO OCT OOT ATC CCA TOC TAA OCA OTA 5. - Crr oOT CCC

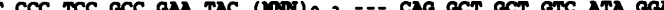
5. - CTT GET CCC TCC OCC GM TAC (20DT) 0-2 ACT CAO OCT OCT OTC ATA COA CTE OCA OTA 5. - CTT OOT CCC TCC OCC OAN TAC (mos) $0-3$-.. CAC OCT OTT ATC CCA TEC

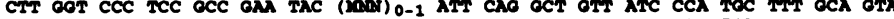
5'- CTT OOT CCC TCC OCC OMA TAC (noas) 0-3 --- OCT ACT ACC TOC ATA TaA

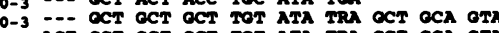
5'- CTT OOT CCC TCC OCC GMA TAC (oOD) $0-2$ AOT OCT OCT OCT TOT ATA TRA CTT eeT CCC TCC eCC GN TAC (zoDr) $0-3$-.- OTA 5 - CTT OOT CCC TCC OCC OMA TAC (MODT) 0-2 AOT OTA ACT

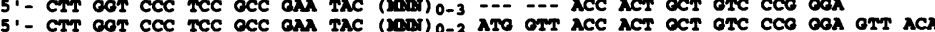
5'- CTT OOT CCC TCC OCC GM TAC (MONS) 0-3 AOC ACC ACC ATA OTA OAG CAO 5':- CTT OOT CCC TCC OCC OAM TAC (moN) $0-3$-1 AOC ACC ACT ATA OOA 5:- CTT OOT CCC TCC OCC OMA TAC (mosi) 0-3 OCC ACT ACC CAT ATA CAO

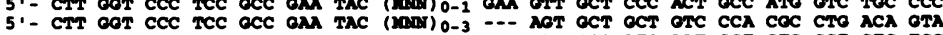
DPL4,5,8,9 DPL6,7 DPL1,2,3 DPL10,11, DPL23 DPL18,19,21 5' - CTT OET CCC TCC OCC OM TAC (MON) $0-1$ GAC TTE OCC ATC NAT COT OTE OCT CTC TCC

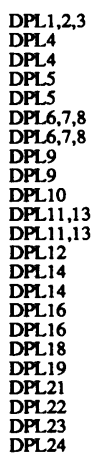

D. Sub-cloning of selected repertoires for expression of soluble Fab fragments

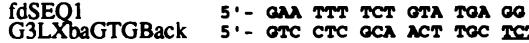

E. Sequencing and probing

TNFCDR3PRB

CK.lib.seg

CH1.lib.seg

peliback

5. - CCT TOE MAO OCA OCA OC

5: - CM CTO CTC ATC AOA TOG CO

5' - OOT OCT CTT COA COA GOG TEC

5' - eNA ATA CCT ATT OCC TAC $\infty$

5':- CAC OMA ACA OCT ATE AC

$\mathrm{A}=$ adenosine $\mathbf{C}=$ cytosine; $\mathrm{G}=$ guanine; $\mathrm{T}=$ thymidine; $\mathrm{Y}=\mathrm{C}$ or $\mathrm{T} ; \mathrm{R}=\mathrm{A}$ or $\mathrm{G} ; \mathrm{W}=\mathrm{A}$ or $\mathrm{T} ; \mathrm{S}=\mathrm{G}$ or $\mathrm{C} ; \mathrm{K}=\mathrm{T}$ or $\mathrm{G} ; \mathrm{M}=\mathrm{C}$ or $\mathrm{A}$ Restriction sites are underlined. Primer names are to the left of the sequences and the $V$-gene segments amplified to the right. 
TG1 (Gibson, 1984) to create the library pUC19-2loxVHlib, and in total $5 \times 10^{8}$ clones were obtained. Diversity was confirmed by Bst NI fingerprinting (Clackson et al., 1991) and sequencing of 24 independent clones. All these clones were found to be different.

\section{Construction of synthetic kappa chain repertoires}

The human $\mathrm{C}_{\mathrm{k}}$ gene was amplified from the vector $\mathrm{pSW} 1 / \mathrm{FabD} 1.3$ (Skerra et al., 1991) by PCR with Taq polymerase using primers CKFOR and $\mathrm{C} \kappa$ Link (Table VBl) which introduce a consensus human $\mathrm{J}_{\mathrm{K}}$ segment at the $5^{\prime}$-end of the $\mathrm{C}_{\mathrm{K}}$ gene and two stop codons (TAA) and an AscI site at the $3^{\prime}$-end. The reaction mixture $(50 \mu \mathrm{l})$ was cycled 25 times $\left(94^{\circ} \mathrm{C}\right.$ for $1 \mathrm{~min}, 60^{\circ} \mathrm{C}$ for $1 \mathrm{~min}, 72^{\circ} \mathrm{C}$ for $\left.1 \mathrm{~min}\right)$. The amplified $\mathrm{C}_{k}$ gene was purified using Magic PCR Preps (Promega) and resuspended in $50 \mu \mathrm{l}$ water.

In parallel, 26 human germline $V_{K}$ gene segments with open reading frames (DPK1-26), which had been cloned from the genomic DNA of a single individual (Cox et al., 1994), were individually amplified with Back primers that introduce an ApaLI site at the $5^{\prime}$-end (see Table VB2) and Forward primers that append a portion of the $\mathrm{J}_{\mathrm{K}}$ segment to the 3 '-end (see Table VB3). For each segment three independent PCRs were performed with different Forward primers to construct CDR3 regions (Kabat et al., 1991) of length eight, nine or 10 residues that included one, two or three residues of random sequence (Figure 1B). For each gene, a $50 \mu \mathrm{l}$ PCR was performed using Taq polymerase and toothpicked frozen glycerol stocks of E.coli infected with the appropriate M13 clone as template. Reactions were cycled 25 times $\left(94^{\circ} \mathrm{C}\right.$ for $1 \mathrm{~min}, 60^{\circ} \mathrm{C}$ for $1 \mathrm{~min}, 72^{\circ} \mathrm{C}$ for $1 \mathrm{~min}$ ). The Forward primers (Table VB3) introduced length and sequence diversity into CDR3 corresponding to that observed in vivo (Kabat et al., 1991).

The amplified $V_{K}$ genes were each joined to the amplified $C_{K}$ gene using PCR (Horton et al., 1989). Assembly PCRs $(25 \mu \mathrm{l})$ used Taq polymerase, $1 \mu \mathrm{l}$ of amplified $C_{K}$ and $0.8 \mu \mathrm{l}$ of the $V_{\kappa}$ gene PCR from above. The appropriate $V_{K}$ Back primer was used for each gene (Table VB2) together with $C_{k}$ FOR (Table VB1) and the reaction cycled 30 times $\left(94^{\circ} \mathrm{C}\right.$ for $1 \mathrm{~min}, 55^{\circ} \mathrm{C}$ for $1 \mathrm{~min}, 72^{\circ} \mathrm{C}$ for $2 \mathrm{~min}$ ).

The PCR assembly reactions for each $V_{\kappa}$ gene were checked by agarose gel electrophoresis, then pooled with the other $V_{\kappa}$ genes according to CDR3 length, and the $\mathrm{V}_{\mathrm{K}}-\mathrm{C}_{\mathrm{K}}$ genes purified using Magic PCR Preps. The pooled DNA was then cut with ApaLI and AscI and digested DNA $(\sim 6 \mu \mathrm{g})$ purified from a $1.5 \%$ low melting-point agarose gel using Magic PCR Preps. Approximately $1 \mu \mathrm{g}$ of the purified and cut $\mathrm{V}_{\mathrm{K}}-\mathrm{C}_{\mathrm{K}}$ DNA from each pool was ligated in a $60 \mu \mathrm{l}$ volume with $1200 \mathrm{U}$ of T4 DNA ligase (New England Biolabs) to $\sim 5 \mu \mathrm{g}$ of digested fdDOG2loxVkdel vector [previously electroeluted from a $0.8 \%$ agarose gel (Sambrook et al., 1990)]. DNA was purified from the ligation mixture using Geneclean II (Bio 101), resuspended in $30 \mu \mathrm{l}$ water, and electroporated (Dower et al., 1988) into four $50 \mu \mathrm{l}$ aliquots of E.coli TG1. Cells were grown in $1 \mathrm{ml} 2 \times$ TY broth containing $1 \%$ glucose for $1 \mathrm{~h}$ and then plated in $243 \mathrm{~mm} \times 243 \mathrm{~mm}$ dishes (Nunc) on TYE (Miller, 1972) medium with $12.5 \mu \mathrm{g} / \mathrm{ml}$ tetracycline (TYE-TET). After overnight incubation at $37^{\circ} \mathrm{C}$, colonies were scraped off the plates into $7 \mathrm{ml}$ of $2 \times \mathrm{TY}$ broth (Miller, 1972) containing $15 \%(\mathrm{v} / \mathrm{v})$ glycerol for storage at $-70^{\circ} \mathrm{C}$.

The frequency of inserts was checked by PCR for each of the three pools and found to be $90 \%$ for CDR3 of eight residues, $100 \%$ for CDR3 of nine residues and $87 \%$ for CDR3 of 10 residues. The number of clones with light chains could then be calculated as $9.9 \times 10^{3}$ (CDR3 of eight residues), $1.5 \times 10^{4}$ (CDR3 of nine residues), $6.5 \times 10^{4}$ (CDR3 of 10 residues). Sequence diversity was confirmed by sequencing eight clones of each CDR3 length; all clones were found to be different. The pools were then combined, to create the library fdDOG-2loxVklib, corresponding to $9.0 \times 10^{4}$ light chains.

\section{Construction of synthetic lambda chain repertoires}

The human C $\lambda 2$ gene (Vasicek and Leder, 1990) was amplified from genomic DNA by PCR with Taq polymerase using primers CL2BACK1 and CL2FOR1 (Table VC1) based in the regions flanking the $\mathrm{C} \lambda 2$ exon. The EcoRI and HindIII sites in CL2FOR 1 and CL2BACK1, respectively, were used to clone the PCR product into M13mp19 (Yanisch-Perron et al., 1985).

Twenty-one $V_{\lambda}$ germline gene segments with open reading frames, previously cloned in M13mpl9 (Williams and Winter, 1993), were individually amplified using PCR and Taq polymerase with back primers (Table VC2) which anneal to framework 1 (FR1) and introduce a 5' ApaLl site, and forward primers (Table VC3) which append a portion of the J $\lambda 2$ gene (Vasicek and Leder, 1990) to CDR3. CDR3 loops (Kabat et al., 1991) of eight to 13 residues that included zero, one, two, three, four or five residues of random sequence were encoded by the forward primers (Figure IC). The number of residues of random sequence included was designed to match the pattern of $\mathrm{V}$ gene rearrangement seen in vivo and varied with the different $V_{\lambda}$ segments used.

Each synthetically rearranged $V_{\lambda}$ gene was individually joined to the human C $\lambda 2$ gene by PCR with Taq polymerase (Horton et al., 1989). Each $50 \mu \mathrm{l}$ PCR assembly reaction contained $\sim 1 \mathrm{ng}$ of $\mathrm{M} 13 \mathrm{mp} 19$ containing the $\mathrm{C} \lambda 2$ gene, $\sim 0.1 \mu \mathrm{g}$ of the $\mathrm{V}_{\lambda}$ gene, the appropriate (FRI) back primer ( $25 \mathrm{pmol}$ ) (Table VC2), the back primer CL2BACK2 (2.5 pmol) (Table $\mathrm{VCl}$ ), which contains the $3^{\prime}$ sequence of the $\mathrm{J} \lambda 2$ gene linked to the $5^{\prime}$ sequence of the $\mathrm{C} \lambda 2$ gene, and the forward primer HUCAFORCYSASCNOT $(25 \mathrm{pmol})$ (Table VCl) which appends two stop codons (TAA) followed by an AscI site to the $3^{\prime}$ of the $\mathrm{C} \lambda 2$ gene. Reactions were cycled 30 times $\left(94^{\circ} \mathrm{C}\right.$ for $1 \mathrm{~min}, 65^{\circ} \mathrm{C}$ for $1 \mathrm{~min}, 72^{\circ} \mathrm{C}$ for $2 \mathrm{~min}$ ).

The PCR assembly reactions were combined into a single pool and the $V_{\lambda}$ genes digested and ligated into fdDOG-2lox $V \kappa$ del as described for the $\mathrm{V}_{\mathrm{K}}-\mathrm{C}_{\mathrm{k}}$ gene pools (see above), thus creating the library fdDOG2lox $V \lambda$ lib. Ninety-two percent of clones were found to carry inserts of the correct size, corresponding to a repertoire size of $7.4 \times 10^{5} \lambda$ light chains. Thirty-three clones were sequenced to confirm the presence of each $V_{\lambda}$ segment. All the sequences were different.

\section{Combinatorial infection and in vivo recombination}

To create a large combinatorial repertoire of heavy and light chains on an fd phage vector we used the strategy of combinatorial infection and in vivo recombination (Waterhouse et al., 1993). This system uses the lox-Cre site-specific recombination system of bacteriophage PI (Sternberg and Hamilton, 1981; Hoess et al., 1982) to bring together heavy and light chain genes onto the same replicon.

Phage P1 lysates were made by thermal induction (Rosner, 1972). E.coli $\mathrm{C} 600 \mathrm{Su}^{-}$(Appleyard, 1954) harbouring phage $\mathrm{PICm} c 1.100$ $\mathrm{r}^{-} \mathrm{m}^{-}$(Yarmolinsky et al., 1989) were grown in a 21 baffled flask containing 11 of $2 \times \mathrm{TY}, 25 \mu \mathrm{g} / \mathrm{ml}$ chloramphenicol, $10 \mathrm{mM} \mathrm{MgSO} 4$ with vigorous shaking at $30^{\circ} \mathrm{C}$ to $\mathrm{OD}_{600}$ of 0.6 . The temperature was then raised quickly to $42^{\circ} \mathrm{C}$ by shaking in a $70^{\circ} \mathrm{C}$ water bath and then shaking continued for a further $35 \mathrm{~min}$ in a $40^{\circ} \mathrm{C}$ water bath. Shaking was then continued at $37^{\circ} \mathrm{C}$ until lysis was visible (usually $\sim 1.5-2 \mathrm{~h}$ ). The culture was then spun at $5000 \mathrm{~g}$ for $15 \mathrm{~min}$ at $4^{\circ} \mathrm{C}$ and $100 \mu \mathrm{l}$ chloroform added to the supernatant. P1 phage titres were measured by adding serial dilutions of the lysate to mid-log phase E.coli TG1 (Gibson, 1984) grown in $2 \times \mathrm{TY}$ broth containing $5 \mathrm{mM} \mathrm{CaCl}$, the mixture incubated for $30 \mathrm{~min}$ at $30^{\circ} \mathrm{C}$ to allow infection and then plated on TYE medium (Miller, 1972) containing $30 \mu \mathrm{g} / \mathrm{ml}$ chloramphenicol. Chloramphenicol resistant colonies were counted after $24 \mathrm{~h}$ incubation at $30^{\circ} \mathrm{C}$. The P1 titre of the lysate used for this library was $3 \times 10^{9}$ transducing units (t.u.) per ml.

$10^{9}$ E.coli TG1, harbouring the library of synthetic $\mathrm{V}_{\mathrm{K}}$ genes (or the library of synthetic $V_{\lambda}$ genes) cloned in fdDOG-2lox $V_{\kappa d e l}$, were used to inoculate 11 of $2 \times \mathrm{TY}$ broth containing $12.5 \mu \mathrm{g} / \mathrm{ml}$ tetracycline $(2 \mathrm{x}$ TY-TET) and the culture shaken for $20 \mathrm{~h}$ at $30^{\circ} \mathrm{C}$ in two $500 \mathrm{ml}$ aliquots in 21 baffled Erlenmeyer flasks. Phage were purified from the supernatant by precipitation with polyethylene glycol as in McCafferty et al. (1990), resuspended in PBS (phosphate buffered saline: $25 \mathrm{mM}$ $\mathrm{NaH}_{2} \mathrm{PO}_{4}, 125 \mathrm{mM} \mathrm{NaCl}, \mathrm{pH} 7.0$ ) and filtered through a $0.45 \mu \mathrm{m}$ sterile filter (Minisart, Sartorius). Phage were titred by infecting exponential phase E.coli $\mathrm{TG} 1\left(30 \mathrm{~min}, 37^{\circ} \mathrm{C}\right)$ and plating on TYE-TET. Yields were typically $10^{10}$ t.u. per $\mathrm{ml}$ of culture.

At various points during the recombination procedure aliquots of bacteria were removed and serial dilutions plated on TYE plates supplemented with $1 \%$ glucose and containing a variety of different antibiotics $(100 \mu \mathrm{g} / \mathrm{ml}$ ampicillin; $15 \mu \mathrm{g} / \mathrm{ml}$ tetracycline; $30 \mu \mathrm{g} / \mathrm{ml}$ chloramphenicol). From the number of colony forming units (c.f.u.) the overall repertoire size could be calculated. These points are indicated in the protocol below and the results are summarized in Table I (also see Results).

Approximately $10^{9}$ E.coli TG1 harbouring the library of synthetic heavy chain genes cloned in pUC19-2loxVHdel (pUC19-2loxVHlib; see above) were used to inoculate $100 \mathrm{ml} 2 \times \mathrm{TY}$ broth containing $100 \mu \mathrm{g} /$ $\mathrm{ml}$ ampicillin and $1 \%(\mathrm{w} / \mathrm{v})$ glucose $(2 \times \mathrm{TY}-\mathrm{AMP}-\mathrm{GLU})$. An aliquot of bacteria was plated for c.f.u. determination (see Table I, sample point 1) and the rest of the culture grown overnight at $30^{\circ} \mathrm{C}$. An aliquot of bacteria was then plated for c.f.u. determination (see Table I, sample point 2). Two $5 \mathrm{ml}$ aliquots of the overnight culture were then used to inoculate two $500 \mathrm{ml}$ aliquots of $2 \times \mathrm{TY}-\mathrm{AMP}-\mathrm{GLU}$ in 21 Erlenmeyer flasks and the cultures grown, shaking, at $37^{\circ} \mathrm{C}$ to an $\mathrm{OD}_{600}$ of 0.5 .

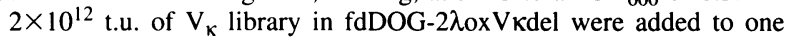


of the above cultures and $2 \times 10^{12}$ t.u. of $\mathrm{V}_{\lambda}$ library in fdDOG-2lox $\mathrm{V} \kappa \mathrm{del}$ were added to the other culture. Each culture was immediately split into $5 \times 100 \mathrm{ml}$ aliquots and each aliquot mixed with 11 of $2 \times \mathrm{TY}-\mathrm{AMP}-$ $\mathrm{GLU}$, pre-warmed to $37^{\circ} \mathrm{C}$. These cultures were then incubated at $37^{\circ} \mathrm{C}$, without shaking for $30 \mathrm{~min}$, and then with shaking until an $\mathrm{OD}_{600}$ of 0.4 was reached $(\sim 30 \mathrm{~min})$. An aliquot of bacteria from the kappa infection and another from the lambda infection were plated for c.f.u. determination (see Table I, sample point 3 ).

$\mathrm{CaCl}_{2}$ was then added to a final concentration of $5 \mathrm{mM}$ and $200 \mathrm{ml}$ phage $\mathrm{P} 1 \mathrm{Cm} c 1.100 \mathrm{r}^{-} \mathrm{m}^{-}$lysate $\left(6 \times 10^{11}\right.$ t.u. see above) were added to each 11 flask (giving a multiplicity of infection of $\sim$ ). Incubation was continued at $30^{\circ} \mathrm{C}$ for $1 \mathrm{~h}$, with a short burst of shaking every 15 $\mathrm{min}$. The culture was then centrifuged at $5000 \mathrm{~g}$ for $15 \mathrm{~min}$ and the pellets resuspended in the original volume of $2 \times \mathrm{TY}$ broth containing $100 \mu \mathrm{g} / \mathrm{ml}$ ampicillin, $12.5 \mu \mathrm{g} / \mathrm{ml}$ tetracycline, $25 \mu \mathrm{g} / \mathrm{ml}$ chloramphenicol and $1 \%$ glucose (i.e. $5 \mathrm{I}$ for the $\mathrm{V}_{\mathrm{\kappa}}$ library and $5 \mathrm{I}$ for the $\mathrm{V}_{\lambda}$ library). An aliquot of bacteria was plated for c.f.u. determination (see Table I. sample point 4). The repertoire size was determined to be $6.5 \times 10^{10}$ from the number of ampicillin, tetracycline and chloramphenicol resistant c.f.u. at this point (see Results). An aliquot of each culture was also centrifuged at $12000 \mathrm{~g}$ for $5 \mathrm{~min}$ and the supernatant filtered through a $0.45 \mu \mathrm{m}$ sterile filter (Minisart, Sartorius). The fd phage in the supernatant were titred by infecting exponential phase E.coli TG1 $\left(30 \mathrm{~min}, 37^{\circ} \mathrm{C}\right)$ plating on TYE-TET (see Table I, sample point 5).

The cultures were incubated overnight at $30^{\circ} \mathrm{C}$ with shaking for $24 \mathrm{~h}$ in $2 \mathrm{I}$ baffled flasks ( $1 \mathrm{I}$ medium per flask). An aliquot of bacteria from each culture was plated for c.f.u. determination (see Table I, sample point 6 ). The fd phage in the supernatant were also titred by infection of exponential phase E.coli TGl as above (see Table I, sample point 7). The total yield of fd phage was $4.1 \times 10^{13}$ t.u. and therefore $>99.9 \%$ were propagated from bacteria containing the pUC 'donor' vector and phage Pl. The cultures were then centrifuged at $5000 \mathrm{~g}$ for $15 \mathrm{~min}$ at $4^{\circ} \mathrm{C}$ and the fd phage precipitated from the supernatant using polyethylene glycol (McCafferty et al.. 1990) and resuspended in a final volume of $10 \mathrm{ml}$ PBS

Ten 2 I flasks, each containing $112 \times$ TY broth were inoculated with E.coli TGl and grown, shaking, at $37^{\circ} \mathrm{C}$ until an $\mathrm{OD}_{600)}$ of $0.4\left(\sim 4 \times 10^{12}\right.$ bacteria) was reached. Two microlitres of the above recombined $V_{k}$ fd phage $\left(8 \times 10^{11}\right.$ t.u.) were added to $5 \mathrm{l}$ of E.coli and $2 \mathrm{ml}$ of the above recombined $V_{\lambda}$ fd phage $\left(2 \times 10^{12}\right.$ t.u. $)$ were added to the other $5 \mathrm{l}$ of E.coli and the cultures held at $37^{\circ} \mathrm{C}$ for $30 \mathrm{~min}$ without shaking and then for 30 min with shaking. The number of E.coli infected with fd phage was determined by plating bacteria on TYE-TET plates to be $1.7 \times 10^{12}\left(\mathrm{~V}_{\mathrm{\kappa}}\right.$ repertoire $)$ and $1.1 \times 10^{12}\left(\mathrm{~V}_{\lambda}\right.$ repertoire $)$. This exceeds the estimated repertoire size by $>10$-fold, hence maintaining library diversity. Tetracycline was then added to $12.5 \mu \mathrm{g} / \mathrm{ml}$ and the culture shaken for $16 \mathrm{~h}$ at $30^{\circ} \mathrm{C}$. The $\mathrm{V}_{\mathrm{k}}$ culture and the $\mathrm{V}_{\lambda}$ cultures were then centrifuged at $5000 \mathrm{~g}$ for $10 \mathrm{~min}$ and the pellet from each repertoire resuspended in $250 \mathrm{ml} 2 \times \mathrm{TY}$ broth containing $15 \%$ glycerol and stored in $15 \mathrm{ml}$ aliquots at $-70^{\circ} \mathrm{C}$.

Aliquots of the two libraries were also spread on TYE-TET in 243 $\mathrm{mm} \times 243 \mathrm{~mm}$ dishes (Nunc). After overnight incubation at $30^{\circ} \mathrm{C}$ the number of colonies on the large plates was calculated from the number of colonies on small TYE-TET plates on which serial dilutions had been spread. Two plates, one containing $3.5 \times 10^{6}$ colonies of the $V_{k}$ library and the other containing $6.4 \times 10^{6}$ colonies of the $V_{\lambda}$ library were selected, and the bacteria scraped into $10 \mathrm{ml} 2 \times \mathrm{TY}$ broth containing $15 \%$ glycerol. This stock therefore corresponded to a repertoire of $10^{7}$ clones.

\section{Assaying the efficiency of in vivo recombination}

To test the efficiency of replacement of the anti-TNF heavy chain in the 'acceptor' vectors (fdDOG-2loxVklib and fdDOG-2loxV $\lambda$ lib) with synthetic heavy chain from the 'donor' vector (pUC19-2loxVHlib), 250 individual colonies from each of the $V_{\lambda}$ and $V_{k}$ recombined libraries were picked onto TYE-TET plates and grown overnight at $30^{\circ} \mathrm{C}$. Colony hybridization was then performed as in Tomlinson et al. (1992), with a primer (TNFCDR3PRB; Table VE) complementary to the CDR3 region of the anti-TNF heavy chain gene found in the 'acceptor' vectors (fdDOG-2loxV $\lambda$ lib and fdDOG-2loxVklib). Where recombination is successful, the anti-TNF heavy chain gene should be replaced by the synthetic heavy chain from the 'donor' vector. Probing of the colonies indicated that only $12 \mathrm{~V}_{\lambda}$ colonies $(5 \%)$ and $39 \mathrm{~V}_{\kappa}$ colonies $(16 \%)$ retained the original heavy chain. Probing of 250 colonies from each of the $V_{\lambda}$ and $V_{\kappa}$ phage libraries before recombination indicated that, as expected, all colonies harboured the original heavy chain.

Clones lacking the anti-TNF heavy chain gene $\left(42 \mathrm{~V}_{\lambda} .48 \mathrm{~V}_{\kappa}\right)$ were screened by PCR (Güssow and Clackson, 1989) for the presence of heavy chains with the primers pelBback and CH1.lib.seq (see Table VE) and for the presence of light chains with the primers fdPCRback and CK.lib.seq (or C $\lambda$.lib.seq). The probing and PCR screening indicated that in the recombined $\mathrm{V}_{\lambda}$ library, $28 \%$ of clones had acquired a heavy chain from the donor vector and also had a lambda light chain gene: $5 \%$ were unrecombined fdDOG-2loxV $\lambda$ lib; and $67 \%$ had deletions of the light chain, heavy chain or both. For the $\mathrm{V}_{\mathrm{K}}$ library, $28 \%$ of clones had acquired a heavy chain from the donor vector and also had a kappa light chain gene; $16 \%$ were unrecombined fdDOG-2lox Vklib; and $56 \%$ had deletions of the light chain, heavy chain or both. Further cycles of infection (without selection) led to a further decrease in the frequency of phage harbouring heavy and light chain genes, presumably due to competition with deletion phage. Nevertheless, immediately after recombination, for both $V_{\lambda}$ and $V_{\kappa}$ repertoires, we can calculate that $28 \%$ of all fd phage clones had both heavy and light chain genes and that the heavy chain gene derived from the pUC 'donor' vector.

\section{Propagation of phage from the recombined library}

Five litres of $2 \times$ TY - TET were inoculated with a $15 \mathrm{ml}$ aliquot of the recombined $\mathrm{V}_{\mathrm{K}}$ library glycerol stock $\left(5 \times 10^{10}\right.$ c.f.u. $)$ and a further 51 $2 \times$ TY - TET inoculated with a $15 \mathrm{ml}$ aliquot of the recombined $\mathrm{V}_{\lambda}$ library glycerol stock $\left(1 \times 10^{11}\right.$ c.f.u. $)$. The cultures were grown, shaking, overnight at $30^{\circ} \mathrm{C}$ in baffled flasks ( 11 medium per flask). The cultures were centrifuged at $5000 \mathrm{~g}$ for $15 \mathrm{~min}$ at $4{ }^{\circ} \mathrm{C}$ and the fd phage precipitated from the supernatant using polyethylene glycol as in McCafferty et al. (1990) and each repertoire resuspended in a final volume of $10 \mathrm{ml}$ PBS. Total phage yields (from $10 \mathrm{l}$ ) were typically around $10^{14}$ t.u.

\section{Selection of the recombined library on immunotubes}

The phage repertoire was panned using immunotubes (Nunc; Maxisorp) coated with each antigen (Marks et al., 1991; Griffiths et al.. 1993). A range of antigens was used, as described in Table II. Here we have focused on five protein antigens: a mouse monoclonal antibody (NQ11/ 7.22: Griffiths et al., 1984); and four proteins belonging to the kringleserine proteases family (HGF/SF, plasmin, t-PA and u-PA). In addition, selection was performed on two haptens conjugated to BSA (FITC Isomer I and NIP). FITC conjugated to BSA (FITC-BSA; 11.2 FITC groups per BSA molecule) was purchased from Sigma; NIP conjugated to BSA (NIP-BSA) was synthesized by coupling NIP-caproate- $O$ succinimide to BSA (Brownstone et al., 1966) to give 27.9 NIP groups per BSA molecule. Tubes were coated with $10 \mu \mathrm{g} / \mathrm{ml}$ protein or $100 \mu \mathrm{g} /$ $\mathrm{ml}$ hapten-BSA conjugates in PBS overnight at room temperature.

For the first round of selection $0.5 \mathrm{ml}\left(6.4 \times 10^{12}\right.$ t.u. $)$ of the recombined $\mathrm{V}_{\mathrm{K}}$ library and $0.5 \mathrm{ml}\left(7.5 \times 10^{12}\right.$ t.u. $)$ of the recombined $\mathrm{V}_{\lambda}$ library were used per immunotube. For the first two rounds of selection tubes were washed 10 times with PBS, $0.1 \%(\mathrm{v} / \mathrm{v})$ Tween 20 and 10 times with PBS. For subsequent rounds of selection tubes were washed 20 times with PBS, $0.1 \%(\mathrm{v} / \mathrm{v})$ Tween 20 and 20 times with PBS (Griffiths et al., 1993). Phage were eluted with $100 \mathrm{mM}$ triethylamine (Marks et al., 1991). Eluted phage were used to infect $10 \mathrm{ml} \log$ phase E.coli TG1 cells and plated on TYE-TET medium in $243 \times 243 \mathrm{~mm}$ dishes (Nunc). After incubation overnight at $30^{\circ} \mathrm{C}$ the colonies were scraped off the plate into $200 \mathrm{ml} 2 \times \mathrm{TY}-\mathrm{TET}$ and incubated, shaking, at $30^{\circ} \mathrm{C}$ for $\sim 6 \mathrm{~h}$. The culture was centrifuged at $5000 \mathrm{~g}$ for $15 \mathrm{~min}$ at $4^{\circ} \mathrm{C}$ and the fd phage precipitated from the supernatant using polyethylene glycol (McCafferty et al., 1990), each repertoire being resuspended in a final volume of $2 \mathrm{ml}$ PBS. The cell pellet was resuspended in $20 \mathrm{ml} 2 \times \mathrm{TY}$ broth containing $15 \%$ glycerol and a $2 \mathrm{ml}$ aliquot stored at $-70^{\circ} \mathrm{C}$.

One millilitre of these phage $\left(\sim 10^{12}\right.$ t.u. $)$ was used per immunotube for the next round of selection. The library was subjected to four or five rounds of growth and selection for each antigen.

\section{Selection of the recombined library using streptavidin- coated paramagnetic beads}

The library was also selected using soluble biotinylated, hapten-BSA conjugates and streptavidin-coated paramagnetic beads (Hawkins et al., 1992), but with some modifications. FITC-BSA (11.2 FITC:BSA) and NIP-BSA (27.9 NIP-BSA) (see above) were biotinylated using Immunopure NHS-SS-Biotin (sulfosuccinimidyl 2-(biotinamido) ethyl$1.3^{\prime}$-dithiopropionate; Pierce) according to the manufacturer's instructions.

For the first round of selection $0.5 \mathrm{ml}\left(6.4 \times 10^{12}\right.$ t.u. $)$ of the recombined $\mathrm{V}_{\mathrm{K}}$ library and $0.5 \mathrm{ml}\left(7.5 \times 10^{12}\right.$ t.u. $)$ of the recombined $\mathrm{V}_{\lambda}$ library were made up to $2.5 \mathrm{ml}$ with PBS and mixed with $2.5 \mathrm{ml}$ PBS containing $4 \%$ skimmed milk powder, $50 \mu \mathrm{l}$ Tween 20 , and biotinylated hapten-BSA added to give a final concentration of $50 \mathrm{nM}$. The mixture 
was then gently rotated on an inclined wheel for $1 \mathrm{~h}$ at room temperature. $1.5 \mathrm{ml}$ of Dynabeads M-280 coated with Streptavidin (Dynal) [and previously blocked by incubating for $2 \mathrm{~h}$ at $37^{\circ} \mathrm{C}$ with PBS containing $2 \%$ skimmed milk powder ( $2 \%$ MPBS)] were then added and mixing continued for a further 15 min at room temperature. The Dynabeads were then washed a total of 15 times, using a Dynal MPC (Magnetic Particle Concentrator); each wash was with $1 \mathrm{ml}$ PBS or with $1 \mathrm{ml} 2 \%$ MPBS (every third wash). Phage were eluted from the beads by incubating $5 \mathrm{~min}$ at room temperature in $300 \mu \mathrm{l} \mathrm{PBS}, 50 \mathrm{mM}$ dithiothreito (DTT) and the eluate used to infect $10 \mathrm{ml} \log$ phase E.coli TGl cells and plated on TYE-TET in $243 \times 243 \mathrm{~mm}$ dishes (Nunc). Phage were harvested from the plates as above and each repertoire resuspended in a final volume of $2 \mathrm{ml}$ PBS. The cell pellet was resuspended in $20 \mathrm{ml}$ $2 \times \mathrm{TY}$ broth containing $15 \%$ glycerol and a $2 \mathrm{ml}$ aliquot stored at $-70^{\circ} \mathrm{C}$ (see above).

For the second round (and subsequent rounds) of selection $1 \mathrm{ml}$ of phage $\left(\sim 10^{12}\right.$ t.u. $)$ were mixed with $0.5 \mathrm{ml}$ PBS containing $6 \%$ skimmed milk powder, $10 \mu \mathrm{l}$ Tween 20 , and biotinylated hapten-BSA added to give a final concentration of $50 \mathrm{nM}$. Selection was then as above, except that only $300 \mu \mathrm{l}$ of streptavidin-coated Dynabeads M-280 were used. The library was subjected to four or five rounds of growth and selection for each antigen.

\section{ELISA screening of repertoire selections}

'Polyclonal' mixtures of phage produced by re-propagation of the library after each round of selection were screened for binding to the antigen used for selection and to other control antigens by ELISA. The phage ELISA was performed essentially as McCafferty et al. (1990) using $10 \mu \mathrm{l}$ PEG precipitated phage $\left(\sim 10^{10}\right.$ t.u. $)$, but using horseradish peroxidase conjugated anti-sheep antibody (Sigma) and $3^{\prime}, 3^{\prime}, 5^{\prime}, 5^{\prime}$ tetramethylbenzidine (TMB) for detection. Reactions were stopped by the addition of $\mathrm{H}_{2} \mathrm{SO}_{4}$ after $10 \mathrm{~min}$ and readings taken by subtracting the $A_{650}$ from the $A_{450}$. All antigens were coated at $10 \mu \mathrm{g} / \mathrm{ml}$ in PBS.

Single tetracycline resistant colonies from infection of E.coli TG1 with eluted phage were also screened to identify those producing antigenbinding phage by ELISA essentially as in Clackson et al. (1991) except that phage were grown at $30^{\circ} \mathrm{C}$, and detection was as for the polyclonal phage ELISA above.

\section{Sub-cloning of selected repertoires for expression of soluble Fab fragments}

Approximately $10^{8}$ bacteria harbouring phage fd were taken from the stocks frozen down after the appropriate round of selection $(5 \mu \mathrm{l}$ of a 10 -fold dilution of the frozen stock). In general, these bacteria were used as template in a $50 \mu \mathrm{l} \mathrm{PCR}$ reaction and the heavy chain genes amplified by pre-soaking at $94^{\circ} \mathrm{C}$ for $10 \mathrm{~min}$ and then cycling 30 times $\left(94^{\circ} \mathrm{C}\right.$ for $1 \mathrm{~min}, 50^{\circ} \mathrm{C}$ for $1 \mathrm{~min}, 72^{\circ} \mathrm{C}$ for $\left.2.5 \mathrm{~min}\right)$ using the primers fdSEQ1 and G3LXbaGTGBack (Table VD). The products were run on a $1.3 \%$ low melting point agarose gel and purified from the gel using 'Magic PCR Preps' (Promega). The DNA was then cut with XbaI and NotI and ligated into pUC119His6mycXba. The ligation mixture was electroporated (Dower et al., 1988) into E.coli TGl and plated on TYE medium containing $100 \mu \mathrm{g} / \mathrm{ml}$ ampicillin and $1 \%$ glucose (TYE-AMP-GLU) and incubated at $37^{\circ} \mathrm{C}$ overnight.

Individual ampicillin resistant colonies were grown in 96-well plates and soluble Fab production induced with isopropyl $\beta$-D-thiogalactoside (IPTG) as in Marks et al. (1991). Soluble Fab fragments in supernatants were assayed for binding to antigen coated plates by ELISA. All antigens were coated at $10 \mu \mathrm{g} / \mathrm{ml}$ in PBS. Bound Fabs were detected with a mixture of rabbit anti-human $\lambda$ light chain antibodies and rabbit antihuman $\kappa$ light chain antibodies (Dako) followed by goat anti-rabbit IgG (whole molecule) peroxidase conjugate (Sigma), or by using a mixture of peroxidase conjugated sheep anti-human $\kappa$ light chain (free and bound) antibodies and peroxidase conjugated sheep anti-human $\lambda$ light chain (free and bound) antibodies (The Binding Site). ELISAs were developed with TMB as above.

Each antigen-binding clone was streaked on a TYE-AMP-GLU plate and two individual colonies picked and re-assayed for production of antigen-binding Fab fragments as above. Positive clones were stored in $2 \times \mathrm{TY}, 15 \%$ glycerol at $-70^{\circ} \mathrm{C}$.

\section{Sequencing of antibody $\boldsymbol{V}$ genes}

Clones, toothpicked from frozen glycerol stocks, were amplified by PCR using Taq polymerase. Reactions $(50 \mu \mathrm{l})$ were pre-soaked for $10 \mathrm{~min}$ at $94^{\circ} \mathrm{C}$ and then cycled 25 times $\left(94^{\circ} \mathrm{C}\right.$ for $1 \mathrm{~min}, 55^{\circ} \mathrm{C}$ for $1 \mathrm{~min}, 72^{\circ} \mathrm{C}$ for $30 \mathrm{~s}$.). The primers were CK.lib.seq and LMB3 for kappa chain amplification; C $\lambda$.lib.seq and LMB3 for lambda chain amplification; and $\mathrm{CH} 1$.lib.seq and pelBback for heavy chain amplification (Table VE). Aliquots of the product were analysed on a 1.3\% agarose gel. The remaining product was purified using Magic PCR Preps (Promega).

PCR cycle sequencing reactions with fluorescent dideoxy chain terminators (Applied Biosystems) $\left(20 \mu \mathrm{l}\right.$ in 25 cycles: $96^{\circ} \mathrm{C}$ for $30 \mathrm{~s}$, $50^{\circ} \mathrm{C}$ for $15 \mathrm{~s}, 60^{\circ} \mathrm{C}$ for $4 \mathrm{~min}$ ) were carried out according to the manufacturer's instructions. The purified PCR product from above (200 ng) was used as template with the following primers: Cr.lib.seq for kappa chains, C $\lambda$.lib.seq for lambda chains and $\mathrm{CH} 1$. lib.seq for heavy chains (Table VE).

The sequencing reactions were analysed on an Applied Biosystems 373A Automated DNA Sequencer. Sequence analysis was performed using SeqEd (Applied Biosystems) and MacVector (IBI Kodak, New Haven, CT)

\section{Epitope mapping of Fab fragments binding monoclonal antibody NQ11/7.22}

The repertoire selected on the mouse monoclonal antibody NQ11/7.22 $(\gamma 1, \kappa ;$ Griffiths et al., 1984) was sub-cloned after the second, third and fourth round of selection for production of soluble Fab fragments. 161 out of 384 clones bound to NQ11/7.22 (see above), and were further mapped by binding to MOPC21 (an unrelated mouse $\gamma 1, \kappa$ monoclonal antibody; Sigma); mouse Fc fragment (Jackson); and NQ11/7.22 zerolinker diabody (containing only the heavy and light chain variable domains; Holliger et al., 1993). All proteins were coated at $10 \mu \mathrm{g} / \mathrm{ml}$ in $50 \mathrm{mM} \mathrm{NaHCO}$ ( $\mathrm{pH} \mathrm{8.3)}$. Eleven different Fab fragments identified by sequencing (Table III) were thereby directly mapped to binding to the Fv (idiotypic) or Fc regions, or to the remaining portions of the monoclonal antibody.

\section{Purification of Fabs and affinity determination}

Several pUC119His6mycXba clones encoding NIP and fluorescein specific Fab fragments were chosen at random for affinity determination. A 11 culture of E.coli TG1 (Gibson, 1984) harbouring each plasmid was grown and Fab expression induced with IPTG (De Bellis and Schwartz, 1990). After induction, the culture was shaken for $3 \mathrm{~h}$ at $25^{\circ} \mathrm{C}$ and the Fab fragments harvested from the periplasm, essentially as in Breitling et al. (1991)

The antibodies were purified by IMAC (Hochuli et al., 1988; Hoffmann and Roeder, 1991). The pooled 'periplasmic fraction' and 'osmotic shock fraction' were passed over a $5 \mathrm{ml} \mathrm{Ni}-\mathrm{NTA}$ resin (Diagen) according to the manufacturer's instructions. The column was washed with $50 \mathrm{mM}$ sodium phosphate buffer $\mathrm{pH} 7.5,500 \mathrm{mM} \mathrm{NaCl}, 35 \mathrm{mM}$ imidazole and the protein was eluted by applying $50 \mathrm{mM}$ sodium phosphate buffer $\mathrm{pH}$ $7.5,500 \mathrm{mM} \mathrm{NaCl}$ and $100 \mathrm{mM}$ imidazole. The eluted protein was dialysed against $2 \times 31$ PBS for $\sim 24 \mathrm{~h}$. The dialysed fractions were then analysed by SDS-PAGE (Laemmli, 1970) under non-reducing conditions and the concentration determined spectrophotometrically (assuming $A_{280}$ of $1.0=0.7 \mathrm{mg} / \mathrm{ml}$ ).

Affinities of the purified Fabs were determined by fluorescence quench titration with free hapten (Eisen, 1964), essentially as described by Foote and Milstein (1991). The haptens used were fluorescein (Sigma) or NIP-CAP. All measurements were made with a Hitachi F-4500 spectrofluorimeter, using an excitation wavelength of $280 \mathrm{~nm}$ and monitoring emission at $340 \mathrm{~nm}$. Antibody $(1.0 \mathrm{ml})$ in PBS was placed in a 10 $\mathrm{mm} \times 10 \mathrm{~mm}$ cuvette in the instrument, mixed continually using a magnetic stir-bar, and held at $20^{\circ} \mathrm{C}$. Hapten additions were made automatically using a $50 \mu \mathrm{l}$ gastight syringe (Hamilton) driven by a Microlab $M$ syringe controller (Hamilton). The titrations and data collection were performed automatically using a Dell 433/L computer interfaced with the syringe controller (through an RS-232 interface) and the spectrofluorimeter (through an IEEE interface and an instrument driver supplied by the manufacturer). The computer was programmed in QuickBasic (Microsoft). Data were averaged from two to five runs.

The binding of three of the Fab fragments binding protein antigens were analysed by SPR using the BIAcore system (Pharmacia Biosensor). The active concentrations of purified Fab fragments NMLl (anti-NQ11/ 7.22 Fv); NML9 (anti-NQ11/7.22 Fc) and MH22 (anti-HGF/SF) were determined by the measurement of mass transport-limited binding slopes (Karlsson et al., 1993). The antibody NQ11/7.22 was purified from ascites by affinity chromatography (Mäkelä et al., 1978) and 990 resonance units (RU) immobilized on the biochip by chemical coupling with NHS/EDC (Johnsson et al., 1991; Chaiken et al., 1992). HGF/SF was immobilized on the biochip after biotinylation. Thus $3.8 \mathrm{kRU}$ of immobilized streptavidin (O'Shannessy et al., 1992) were used to capture 
2800 RU HGF which had been biotinylated with biotin-LC-hydrazide (Pierce) after periodate oxidation of the carbohydrate using a protocol based on O'Shannessy (1990), but with $20 \mathrm{mM} \mathrm{Na} 2 \mathrm{SO}_{3}$ to quench excess periodate (Weber and Hof, 1975). After capture the hydrazone bond between the biotin and the HGF was stabilized by reduction with sodium cyanoborohydride $(0.1 \mathrm{M}$ in $0.1 \mathrm{M} \mathrm{Na}$ acetate $\mathrm{pH} 4: 40 \mu \mathrm{l}$ at 2 $\mu \mathrm{l} / \mathrm{min}$ ). The fragments were passed over the surface at $5 \mu \mathrm{l} / \mathrm{min}$ at $25^{\circ} \mathrm{C}$ in concentrations ranging from 2 to $400 \mathrm{nM}$, and the dissociation constant determined by Scatchard analysis of the equilibrium binding, and on- and off-rate constants by a kinetics analysis software (Pharmacia Biosensor) (Karlsson et al., 1991; Chaiken et al., 1992).

\section{Acknowledgements}

We thank M.Yarmolinsky and N.Sternberg for helpful advice and the gift of several phage P1 strains. Also R.A.Mariuzza, S.Songsivilai, M.Bowles, V.V.Mesyanzhinov, K.P.Holliger, R.Hoet, R.de Wildt, C.de Lalla and D.Neri for practical help with the library construction and selection. A.D.G. was supported by the Cancer Research Campaign, O.H. and S.C.W. by MRC studentships, W.L.C. by the Plant Biotechnology Institute, National Research Council of Canada, P.W. by CSIRO Australia, I.M.T. by the Human Genome Mapping Programme and by Trinity College Cambridge, R.E.K. by Deutsche Forschungsgemeinschaft, N.M.L. by The Cambridge Commonwealth Trust, A.N. by the Human Frontier Science Programme Organization (HFSPO), J.P.L.C. by the Nuffield Foundation and M.Z. by the CEC BIOTECH programme.

\section{References}

Appleyard,R.K. (1954) Genetics, 39, 440-452.

Barbas,C.F., Kang,A.S., Lerner,R.A. and Benkovic,S.J. (1991) Proc. Natl Acad. Sci. USA, 88, 7978-7982.

Barbas,C.F. et al. (1992a) Proc. Natl Acad. Sci. USA, 89, 9339-9343.

Barbas,C.F.. Crowe.J.E., Cababa,D.. Jones,T.M., Zebedee,S.L., Murphy,B.R., Chanock,R.M. and Burton,D.R. (1992b) Proc. Natl Acad. Sci. USA, 89, 10164-10168.

Barbas,C.F., Bain,J.D., Hoekstra,D.M. and Lerner,R.A. (1992c) Proc. Natl Acad. Sci. USA, 89, 4457-4461.

Barbas,C.F., Amberg,W., Simoncsits.A., Jones,T.M. and Lerner,R.A. (1993) Gene, 137, 57-62.

Bates,R.M., Ballard,D.W. and Voss,E.W. (1985) Mol. Immunol., 22, 871-877.

Bedzyk,W.D., Reinitz.D.M. and Voss,E.W. (1986) Mol. Immunol., 23, 1319-1328.

Bothwell,A.L.M., Paskind,M., Reth,M., Imanishi-Kari,T., Rajewsky,K. and Baltimore,D. (1981) Cell, 24, 625-637.

Breitling,F., Dübel,S., Seehaus,T., Klewinghaus,I. and Little,M. (1991) Gene, 104, 147-153.

Brownstone,A., Mitchison,N.A. and Pitt-Rivers,R. (1966) Immunology; 10, 465-481.

Chaiken,I., Rosé,S. and Karlsson,R. (1992) Anal. Biochem., 201, 197210.

Chothia,C. and Lesk,A.M. (1987) J. Mol. Biol., 196, 901-917.

Chothia,C. et al. (1989) Nature, 342, 877-883.

Chothia,C., Lesk,A.M., Gherardi,E., Tomlinson,I.M., Walter,G., Marks,J.D., Llewelyn,M.B. and Winter,G. (1992) J. Mol. Biol., 227, 799-817.

Chuchana,P., Blancher,A., Brockly,F., Alexandre,D., Lefranc,G. and Lefranc,M.P. (1990) Eur. J. Immunol., 20, 1317-1325.

Clackson,T., Hoogenboom.H.R., Griffiths,A.D. and Winter,G. (1991) Nature, 352, 624-628.

Cox,J.P.L., Tomlinson,I.M. and Winter,G. (1994) Eur. J. Immunol., 24, 827-836.

Cumano,A. and Rajewsky,K. (1985) Eur. J. Immunol., 15, 512-520.

Cumano,A. and Rajewsky.K. (1986) EMBO J., 5, 2459-2468.

De Bellis,D. and Schwartz,I. (1990) Nucleic Acids Res., 18, 1311.

Denzin,L.K. and Voss,E.W. (1992) J. Biol. Chem., 267, 8925-8931.

Dower,W.J., Miller,J.F. and Ragsdale,C.W. (1988) Nucleic Acids Res., 16. 6127-6145.

Eisen,H.N. (1964) Methods Med. Res., 10, 115-121.

Foote,J. and Milstein,C. (1991) Nature, 352, 530-532.

Garrard,L.J., Yang,M., O'Connell,M.P., Kelley,R.F. and Henner,D.J. (1991) Bio/Technology, 9, 1373-1377.

Gibson.T.J. (1984) PhD thesis, University of Cambridge. UK.

Griffiths,G.M., Berek,C., Kaartinen,M. and Milstein,C. (1984) Nature. 312, 271-275.
Griffiths,A.D. et al. (1993) EMBO J., 12, 725-734.

Güssow,D. and Clackson,T. (1989) Nucleic Acids Res., 17, 4000.

Hawkins,R.E., Russell,S.J. and Winter,G. (1992) J. Mol. Biol., 226, 889-896.

Hochuli,E., Bannwarth,W., Döbeli,H., Gentz,R. and Stüber,D. (1988) Bio/Technology, 6, 1321-1325.

Hoess,R.H., Ziese,M. and Sternberg,N. (1982) Proc. Natl Acad. Sci. USA, 79, 3398-3402.

Hoess,R.H., Wierzbicki,A. and Abremski,K. (1986) Nucleic Acids Res., 14, 2287-2300.

Hoffmann,A. and Roeder,R.G. (1991) Nucleic Acids Res., 19, 6337-6338.

Holliger,P., Prospero,T. and Winter,G. (1993) Proc. Natl Acad. Sci. USA, 90, 6444-6448.

Hoogenboom,H.R. and Winter,G. (1992) J. Mol. Biol., 227, 381-388.

Hoogenboom,H.R., Griffiths,A.D., Johnson,K.S., Chiswell,D.J., Hudson,P. and Winter,G. (1991) Nucleic Acids Res., 19, 4133-4137.

Horton,R.M., Hunt,H.D., Ho,S.N., Pullen,J.K. and Pease,L.R. (1989) Gene, 77, 61-68.

Huse,W.D., Sastry,L., Iverson,S.A., Kang,A.S., Alting,M.M., Burton,D.R., Benkovic,S.J. and Lerner,R.A. (1989) Science, 246, 1275-1281.

Johnsson,B., Löfås,S. and Lindqvist,G. (1991) Anal. Biochem., 198, 268-277.

Kabat,E.A., Wu,T.T., Perry,H.M., Gottesman,K.S. and Foeller,C. (1991) Sequences of Proteins of Immunological Interest. 5th edn, US Dept of Health and Human Services, Bethesda, USA.

Karlsson,R., Michaelsson,A. and Mattsson,L. (1991) J. Immunol. Methods, 145, 229-240.

Karlsson,R., Fägerstam,L., Nilhans,H. and Persson,B. (1993) J. Immunol. Methods, 166, 75-84.

Kranz,D.M. and Voss,E.W. (1981) Mol. Immunol., 18, 889-898.

Kranz,D.M., Herron,J.N. and Voss,E.W. (1982) J. Biol. Chem., 257, 6987-6995.

Laemmli,U.K. (1970) Nature, 227, 680-685.

Lucisano-Valim,Y.M. and Lachmann,P.J. (1991) Clin. Exp. Immunol., 84, 1-8.

Mäkelä,O., Kaartinen,M., Pelkonen,J.L.T. and Karjalainen,K.J. (1978) J. Exp. Med., 148, 1644-1660.

Mariuzza,R. and Strand,M. (1981) Mol. Immunol., 18, 847-855.

Marks,J.D., Hoogenboom,H.R., Bonnert,T.P., McCafferty,J., Griffiths,A.D. and Winter,G. (1991) J. Mol. Biol., 222, 581-597.

Marks,J.D., Hoogenboom,H.R., Griffiths,A.D. and Winter,G. (1992a) J. Biol. Chem., 267, 16007-16010.

Marks,J.D., Griffiths,A.D., Malmqvist,M., Clackson,T., Bye,J.M. and Winter,G. (1992b) Bio/Technology, 10, 779-783.

Marks,J.D., Ouwehand,W.H., Bye,J.M., Finnern,R., Gorick,B.D., Voak,D., Thorpe,S., Hughes-Jones,N.C. and Winter,G. (1993) Bio/ Technology, 11, 1145-1149.

McCafferty,J., Griffiths,A.D., Winter,G. and Chiswell,D.J. (1990) Nature, 348, 552-554.

Miller,J.H. (1972) Experiments in Molecular Genetics. Cold Spring Harbor Laboratory Press, Cold Spring Harbor, NY, USA.

Munro,S. and Pelham,H.R.B. (1986) Cell, 46, 291-300.

Nissim,A., Hoogenboom,H.R., Tomlinson,I.M., Flynn,G., Midgley,C., Lane,D. and Winter,G. (1994) EMBO J., 13, 692-698.

Nossal,G.J. (1993) Ann. N.Y. Acad. Sci., 690, 34-41.

O’Shannessy,D.J. (1990) Methods Enzymol., 184, 162-166.

O'Shannessy,D.J., Brigham-Burke,M. and Peck,K. (1992) Anal. Biochem., 205, 132-136.

Perelson,A.S. and Oster,G.F. (1979) J. Theor. Biol., 81, 645-670.

Rathjen,D.A., Furphy,L.J. and Aston,R. (1992) Br. J. Cancer, 65, 852-856.

Reinitz,D.M. and Voss,E.W. (1984) Mol. Immunol., 21, 775-784.

Rosner,J.L. (1972) Virology, 48, 679-689.

Sambrook,J., Fritsch,E.F. and Maniatis,T. (1990) Molecular Cloning: A Laboratory Manual. Cold Spring Harbor Laboratory Press, Cold Spring Harbor, NY, USA.

Schwartz,R.S. and Stollar,B.D. (1994) Immunol. Today, 15, 27-32.

Skerra,A., Dreher,M.L. and Winter,G. (1991) Anal. Biochem., 196, 151-155.

Smith.G.P. (1985) Science, 228, 1315-1317.

Sternberg,N. and Hamilton,D. (1981) J. Mol. Biol., 150, 467-486.

Tomlinson,I.M., Walter,G., Marks,J.D., Llewelyn,M.B. and Winter,G. (1992) J. Mol. Biol., 227, 776-798.

Tomlinson,I.M., Cook,G.P., Carter,N.P., Elaswarapu,R., Smith,S., Walter,G., Buluwela,L., Rabbitts,T.H. and Winter,G. (1994) Human Mol. Gen., 3, 853-860. 


\section{A.D.Griffiths et al.}

Vasicek,T.J. and Leder,P. (1990) J. Exp. Med., 172, 609-620.

Vieira,J. and Messing,J. (1987) Methods Enzymol., 153, 3-11.

Waterhouse,P., Griffiths,A.D., Johnson,K.S. and Winter,G. (1993) Nucleic Acids Res., 21, 2265-2266.

Weber,P. and Hof,L. (1975) Biochem. Biophys. Res. Commun., 65, 1298-1302.

Williams,S.C. and Winter,G. (1993) Eur. J. Immunol., 23, 1456-1461.

Winter,G., Griffiths,A.D., Hawkins,R.E. and Hoogenboom,H.R. (1994) Annu. Rev. Immunol., 12, 433-455.

Wu,T.T., Johnson,G. and Kabat,E.A. (1993) Proteins, 16, 1-7.

Yanisch-Perron,C., Vieira,J. and Messing,J. (1985) Gene, 33, 103-119.

Yarmolinsky,M.B., Hansen,E.B., Jafri,S. and Chattoraj,D.K. (1989) J. Bacteriol., 171, 4785-4791.

Received on March 2, 1994; revised on May 5, 1994 